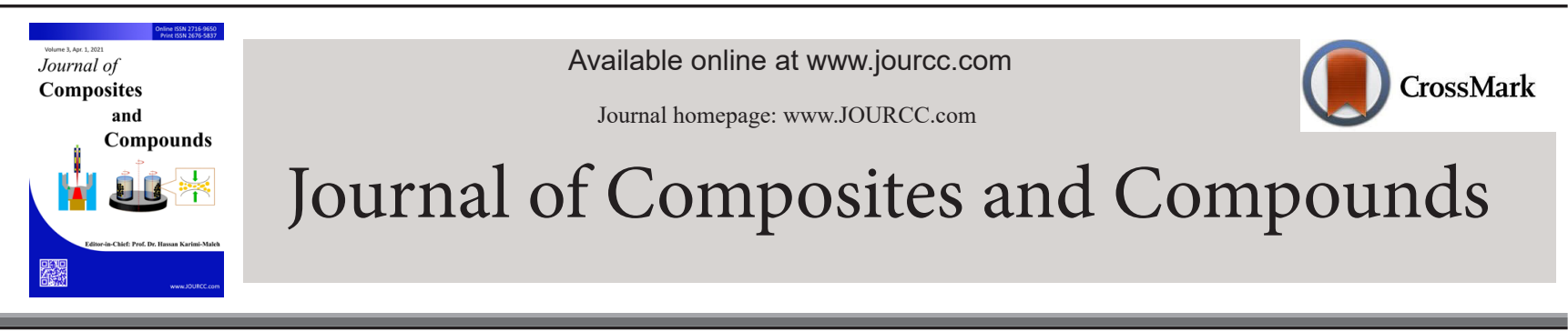

\title{
Sol-gel: Uncomplicated, routine, and affordable synthesis procedure for utilization of composites in drug delivery: Review
}

\author{
Reyhaneh Nasr Azadani ${ }^{a}$, Milad Sabbagh ${ }^{b}$, Haniye Salehi ${ }^{c}$, Amir Cheshmi ${ }^{d *}$, Ali Raza ${ }^{e}$, Beena Kumari ${ }^{f}$,
}

\section{Gisou Erabi ${ }^{g}$}

${ }^{a}$ Department of Biomaterials Nanotechnology and Tissue engineering, School of Advanced Technology in Medicine, Isfahan University of Medical Sciences, Isfahan, Iran

${ }^{b}$ Department of Biomedical Engineering, University of Applied Science and Technology, Tehran, Iran

${ }^{c}$ Department of Physical Education and Sport Science, Faculty of Literature and Humanities, Islamic Azad University, Kerman Branch, Kerman, Iran ${ }^{d}$ Department of Materials Engineering, Babol Noshirvani University of Technology, Shariati Avenue, Babol, Iran

e School of Biomedical Engineering, Shanghai Jiaotong University, Shanghai, China

${ }^{f}$ Department of Pharmaceutical Sciences, Indira Gandhi University, Meerpur, Rewari, Haryana, India

${ }^{g}$ Student Research Committee, School of Medicine, Urmia University of Medical Sciences, Urmia, Iran

A B S T R A C T

Drug delivery is known as an approach for transporting a pharmaceutical compound in animals and the human body to achieve effective therapy. Drug carriers are usually based on nanoparticles synthesized by several methods. The sol-gel method is an inexpensive and simple process to prepare drug carriers that can produce particles Received in revised form 11 February 2021

with a high degree of homogeneity and purity. The process of sol-gel involves hydrolysis, polymerization/conden- Accepted 25 March 2021 sation of monomers, particle growth, and gel formation. The properties of materials including composition and morphology are affected by several factors and can be controlled by the process parameters. Due to the advantages of this method, it is widely used for drug carriers' preparation. In this study, the definition and advantages of the D sol-gel process are discussed. Moreover, drug carriers such as organic-inorganic, silica, and calcium composites, as well as bioactive glass synthesized by this method are reviewed.

(C) 2021 jourcc.

Peer review under responsibility of jourcc
A R T I C LE INFORMATION

Article history:

Received 24 January 2021

Keywords:

Drug carriers

Organic-inorganic composites

Silica composites

Calcium composites

Bioactive glass

Table of contents

1. Introduction .

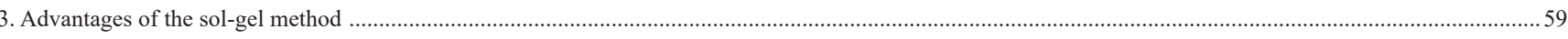

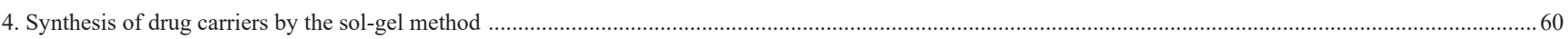

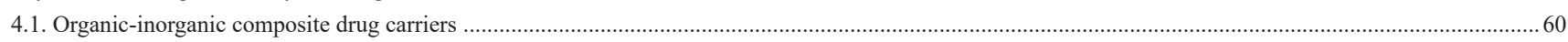

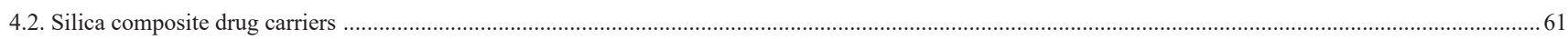

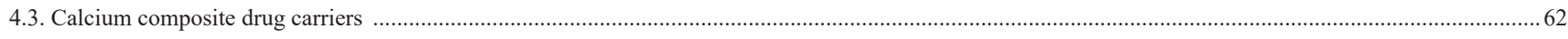

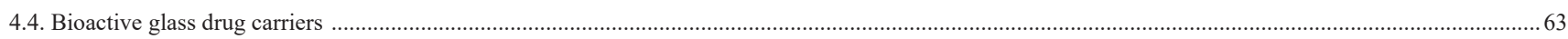

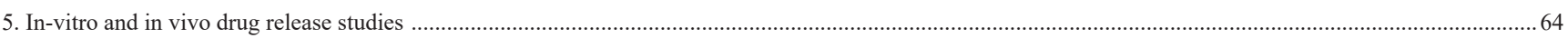

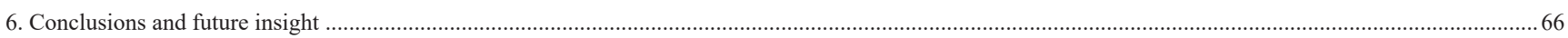

\section{Introduction}

The drug delivery system (DDS) is presented as a technology or method that enables drugs to achieve optimized therapeutic benefits by accurately managing their body distribution profiles. Numerous methods to accomplish an effective treatment since at least the 1970s have been introduced by scientists such as Gregoriadis [1], Zafaroni [2], and Theeuwes [3]. These methods were also explored concisely in the conference held during the same period [4]. The drug delivery system's aims 


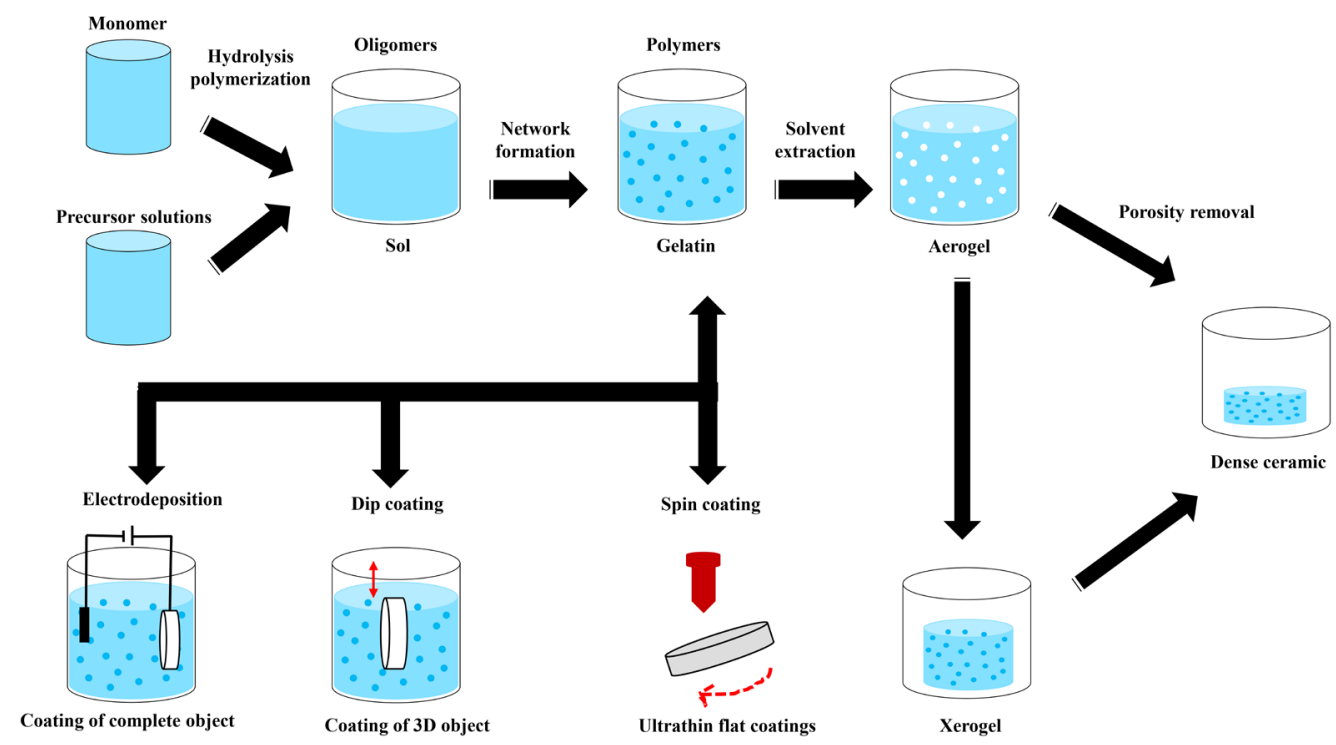

Fig. 1. Synthesis method of sol-gel.

and strategies are often divided into three main areas, i.e., 1) preference of route of administration and improvement of absorption, 2) controlling the release from formulations, and 3) targeting specific site of operation. Different drug delivery techniques for improving absorption [5] and regulated release [6] have been introduced in these respects. In the case of drug targeting, macromolecules including antibodies [7] and particulate vehicles such as liposomes [8] have also been used to build multiple carrier mechanisms for the targeted delivery of specific organs and cells [9]. Many composites have been created and assessed for various biomedical applications, such as tissue engineering, cardiac prosthesis, and drug delivery in the last few years [10-14]. For example, the composite's composition must contain an acid-resistant lipids exterior protecting the lactate dehydrogenase (LDH) interlayers for supplying medicine to the intestines [15].

Many synthesis approaches have been introduced for producing these biomaterials, such as co-precipitation, in-situ gelling, microemulsion, electrospinning, solvothermal, microwave emission, and double emulsion of water-in-oil-in-water (w/o/w), free polymerization of radicals, and sol-gel. The sol-gel procedure is flexible and straightforward among the afore-mentioned methods; the components of the process are cheap, inert, resilient to light and heat, and harmless to the ecosystem or humans $[16,17]$. The sol-gel approach allows the manufacturing of homogeneous drug delivery nanoparticles and enables the processing of optimum temperature required for the treatment of biological products, to regulate the size and releasing rate [18]. The sol-gel system has attracted the attention of many scientists in the medical sector in recent years [19-21]. The term refers to a low-temperature process that uses chemical components that can create uniform and pure glasses and ceramics [22].

In biotechnology applications in which biomolecules, including proteins, enzymes, and antibodies, are incorporated into the sol-gel matrix have lately been widely investigated [23]. The notion was proposed in 1983 by Unger et al. [24] using sol-gel-based silica in drug delivery applications. Furthermore, numerous sol-gel-based compounds are bioactive; they can bind to human tissues such as bone. These remarkable biomaterials have osteoconductive qualities and can be used in vivo. For both therapeutic strategies (gene/drug delivery) as well as diagnosis (imaging), nanoparticles are proven to have potential to be used as intravascular or cellular probes which could play a crucial role in bio-medicine [25]. However, the efficiency of synthetic biomaterials relies signifi- cantly on the synthesized powders' overall features and qualities. These characteristics include purity, the structure of the phase, density, crystallinity, size of the particle, particle size arrangement, specific surface area, and geometry of particles [26].

The sol-gel methodologies have been used during the last few decades to produce several mixed-metal oxides, nanoporous oxides, nanomaterials, nanoscale structures, organic-inorganic hybrids, nanocoatings, glasses, amorphous, monolithic and structured composite, organic metal assemblies, and bioinspired materials [27-30]. It is an interesting strategy for the preparation of hybrid materials as it occurs in a solution, effortlessly implementing organic phases into an inorganic material, and at the same time, inhibiting degradation [31]. The reactions that happen during the sol-gel procedure are (i) solution-forming by hydrolysis of alkoxide precursors (sol phase) and (ii) condensation of the transitional species causing 3D network formation (gel phase) [32]. In this paper, the sol-gel synthesis method for applying composites in drug delivery, the fabrication of drug carriers through this technique, and its benefits are described in depth.

\section{Principle of the sol-gel method}

The science of sol-gel dates back to more than 150 years ago. During his experiments on silica sols, Graham first invented the word "sol-gel" in 1864 [33]. While van Helmont discovered "water glass" in 1640 by dissolving silicate substance in alkali and followed by precipitating silica gel in the acidic environment, it was in 1846 that Ebelmen witnessed transparent glass creation. After exposure to a silane atmosphere derived from $\mathrm{SiCl}_{4}$ and ethanol [34, 35], real sol-gel research was started for the first time. During the doctoral courses at the University of Goettingen in 1912-1915, Patrick developed a cost-effective and fast sol-gel process to manufacture massive silica gel amounts from sodium silicate $\left(\mathrm{Na}_{2} \mathrm{SiO}_{3}\right)$ [36]. Besides, by supercritical drying of the gel produced by hydrolytic polycondensation of $\mathrm{Si}(\mathrm{OH})_{4}$, Kistler [37] presented the first synthesis of a highly porous silica form $\left(\mathrm{SiO}_{2}\right)$, which he called "aerogel". Solgel techniques also allow for powderless manufacturing, directly from solution, glasses, thin fibers or films, and ceramics. Precursors are combined at the molecular level, and alternately structured materials can be formed at far lower temperatures than conventional processing methods can offer [38]. 
Generally, in the sol-gel procedure, the phase transformation from a liquid "sol" (mostly colloidal) to a solid "gel" of a system is required. For the sol's preparation, metal-organic compounds or inorganic metal salts like metal alkoxides $[\mathrm{M}(\mathrm{OR}) \mathrm{n}]$ are used as the initial materials. $\mathrm{M}$ demonstrates network-forming elements like $\mathrm{B}, \mathrm{Al}, \mathrm{Zr}, \mathrm{Ti}, \mathrm{Si}$, etc. and $\mathrm{R}$ is commonly an alkyl group. Tetramethyl-orthosilicate (TMOS) and Tetraethyl-orthosilicate (TEOS) in the sol-gel method are the most widely utilized precursors. Since metal alkoxide is combined with a mutual solvent (often alcohol) and water in the base/acid catalyst presence leading to the initiation of the simple sol-gel reaction [39-41].

Normally, after the hydrolysis process is triggered, the condensation and hydrolysis reactions proceed simultaneously. The hydrolysis contributes to creating siloxane bonds ( $\mathrm{Si}-\mathrm{O}-\mathrm{Si}$ ) and silanol groups ( $\mathrm{Si}-\mathrm{OH})$ formed by condensation reactions, leading to the water and alcohol production as by-products. The final material characteristics and composition are considerably affected by the chemical reactions that happen throughout the sol-gel process. Additional processing of the sol allows one to render materials of sol-gel in various configurations. With dip, spin, and spray coating, thin films could be formed on a substrate [42, 43].

The solution's viscosity increases steadily during the sol-gel transition as the sol begins to become interconnected to make a stable and porous gel network. The gel may be transformed into rigid glass particles or ceramic with more drying and heat processing (at atmospheric pressure) resulting in considerable shrinkage due to the solvent liquid removal. The obtained substance is recognized as "xerogel". The network does not get smaller and an extremely porous, low-density substance called aerogel is processed if solvent elimination happens within hypercritical (supercritical) settings [44, 45]. Viscous sintering (xerogel shrinkage because of a limited viscous flow) is caused by thermal processing of the xerogel at high temperatures, and the porous gel is appropriately converted into a thick glass [46] (Fig. 1).

When the sol viscosity is calibrated to a suitable viscosity level, it is possible to obtain ceramic fibers from the sol. Through precipitation, emulsion methods, or spray pyrolysis, ultra-fine, and homogenous ceramic powders are produced. Applications such as using sol-gel as the porous membrane to the encapsulation of enzymes, sensor molecules, and several other substances are most prevalent, while many applications of sol-gel-derived composites are rapidly developing in biomedical uses $[47,48]$.

The creation of new biomaterials is needed for biomedical applications, and it can be accomplished by combining sol-gel biochemistry and chemistry. Gel-derived substances are ideal platforms for analyzing and regulating biochemical interactions due to their micro-pores, broad specific surface, and residual hydroxyl ions inside constrained matrices with boosted bioactivity [49]. The coating of medical instruments is an essential factor in all biomedical applications. Materials utilized in medical tools must have suitable structural and technical qualities and they preferably facilitate the healing response with no triggering severe physiological reactions [50]. Medical device manufacturers use different surface treatments, like coatings, to improve or alter characteristics, including hydrophobicity/hydrophilicity, biocompatibility, functionality, and lubricity. For diverse biomedical uses, sol-gel processing provides an alternative strategy for creating bioactive surfaces. A variety of benefits are provided by sol-gel thin film development, such as low-temperature production, simplicity of manufacturing process, and accurate chemical and microstructural regulation [51].

The sol-gel-derived layers or films have substantial biocompatibility, large specific surface areas (they can be utilized as an adsorbed drug carrier), and an outer surface where rich chemistry facilitates appropriate biomolecules for effective functionalization [52]. The regulation of the silica coating's thickness and pore-size distribution also offers a systematic approach to control the duration and amount of drug release [53].
The drug diffusion and release rate are associated with both the porosity and thickness of coated films, which can be managed by the sol-gel dip-coating method by the sol composition and withdrawal speed. The benefits of applying the sol-gel dip-coating approach are that it is not reliant on the morphology of the material and it is possible to manage surface characteristics and a high level of homogeneity of thickness [54, $55]$.

One of the most promising drug delivery platforms is the sol-gel approach. In general, the formation of sol-gel is known as a chemical processing technique for the development of ceramic materials through implementing three significant steps: (i) solvent formulation, (ii) solvent gelation, and (iii) solvent elimination. Currently, the sol-gel method is proved to be a potential technological area, as its multifunctionality enables scientists to produce a wide variety of materials characterized by specific microstructures and nanostructures [38], ideal for the development of many innovative products, such as fibers [56], industrial coatings [57], and films. Actually, by employing lower manufacturing temperatures than those implicated in conventional ceramic powder consolidation or glass melting methods, the sol-gel approach allows highly uniform and chemically pure materials to be obtained [58].

In the biomedical industry, the sol-gel approach reveals its potential specifically to manufacture bioactive glasses in the form of inherently nanoporous materials capable of optimizing bioactivity and cellular response due to its distinctive material characteristics, including large specific surface area than conventional methods used products [20,59]. Besides, sol-gel technology provides the opportunity to generate hybrid materials firmly bonded at the nanoscale consisting of inorganic and organic basis, eliminating the shortcomings of conventional multiphasic composites $[60,61]$

\section{Advantages of the sol-gel method}

The sol-gel method is a significant development in science demanding a multidisciplinary strategy with its numerous uses. It produces ceramic and glass materials at comparably lower temperatures that enable the loading of different organic and inorganic materials and biomolecules during the glass structuring. The sol-gel method was recognized since the 1800s, but the uses of sol-gel have expanded several times over the last two decades. It has been employed for the manufacturing of optical coatings, optical fibers, electro-optic products, powders of colloidal silica for stationary as catalytic support and chromatographic phase, nanoporous carbon xerogels, and aerogels as hydrogen storing substances, nanocrystalline semiconductor-doped xerogels, luminescence concentrators, active waveguides, semiconducting tools, adjustable lasers, and sunscreen. Precise sol-gel technology uses are continually evolving in nanotechnology, biomedical equipment, environmental control, and defense [39, 62].

The sol-gel process, which enables the regulation of complex oxides stoichiometry and the development of high-purity, uniform, and crystalline nanoparticles under mild reaction conditions, is among the most flexible synthesis methods [63]. The sol-gel technique has many benefits, such as the pure quality of products and the potential of incorporating thermolabile molecules, among the most significant ones. In reality, inorganic-organic hybrid materials [64] can be obtained in which the organic and inorganic phases are linked to sub-micrometer levels at the nanometer [65].

Fascinating biomaterials for a range of clinical and biomedical applications have been suggested in the past few years for ceramics, drug delivery systems, and glasses provided by integrating polymers or drugs into the inorganic matrix $[64,66]$, or nanocomposites generated from hybrid materials, all designed by this model. For example, they have been used as knee and hip implants or cardiac valves $[55,67]$. 


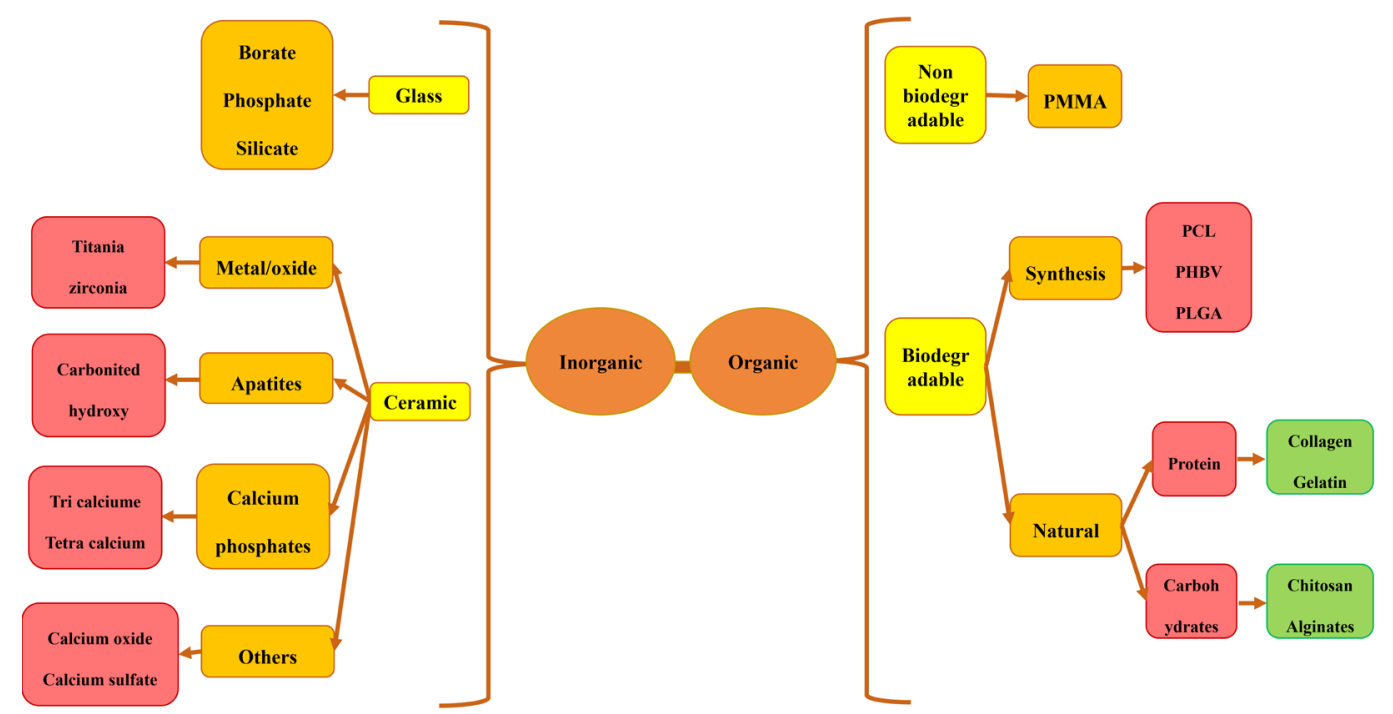

Fig. 2. Possible organic-inorganic combinations for drug delivery.

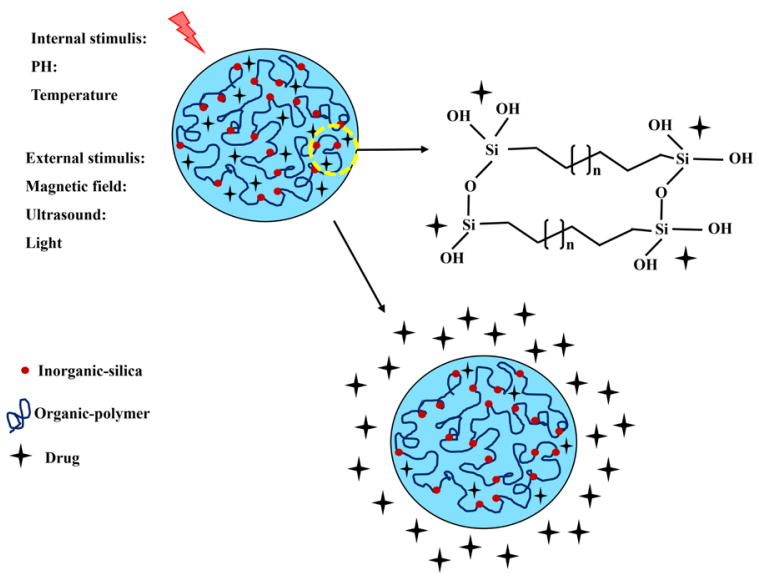

Fig. 3. Mechanism of organic-inorganic systems of drug delivery.

\section{Synthesis of drug carriers by the sol-gel method}

\subsection{Organic-inorganic composite drug carriers}

Recently, various prospective composites have been prepared, developed, and investigated for biomedical applications such as biosensors, artificial blood vessels, stem cell therapy, cancer therapy, immunotherapy, antimicrobial properties, enzyme immobilization, wound dressings, cardiac prosthesis, tissue engineering, drug delivery, and etc.[68-71]. The choice of an inorganic-organic composite would be more logical than that of a single type carrier material. Composites are supposed to provide required mechanical strength, boosted tissue integration, and prolonged and effective drug release, consisting of several phases combined to provide better performance. Fig. 2 demonstrates several potential formulations for bone drug delivery in the creation of inorganic-organic composites.

Organic-inorganic hybrid composites produced through the sol-gel method are of great interest. Firstly, a uniform sol that converts into a gel is provided. After that, the controlled drying process happen to produce a monolith or powder. The sol-gel composition is stablished on polycondensation and metal alkoxides $\mathrm{M}(\mathrm{OR})_{\mathrm{x}}$ hydrolysis, where $\mathrm{M}$ $=\mathrm{Si}, \mathrm{Zr}, \mathrm{Ti}, \mathrm{Al}$. and $\mathrm{R}=$ any alkyl group. Hydrolysis that causes OR group replacement connected to $\mathrm{M}$ by $\mathrm{M}-\mathrm{OH}$ groups, is the initial reaction. As before, these chemical species can interact together to build M-O-M bonds, leading to metal network establishment. This stage creates a three-dimensional network with the solvent used in these processes residing inside the structure's pores. Organic-inorganic composites were produced by Catauro et al. [72] through the sol-gel technique. The drug was applied throughout the sol-gel procedure, with $\mathrm{TiO}_{2}$ and poly ( $\varepsilon$-caprolactone) (PCL) glass acting as inorganic and organic phases. A similar technique was developed to produce composite films of silica and Poly(methyl methacrylate) (PMMA) by Lin et al. [73] and zirconia and PCL by Catauro et al. [74]. However, the sol-gel interactions are influenced by several factors, including composition and concentration of the solvents, reactants, catalysts, process temperature, solvent elimination speed, and drug release pace by inorganic material and binding operative material. The procedure is sluggish and requires hazardous chemicals to be used [73]. Fig. 3 illustrates the general mechanism of organic-inorganic systems of drug delivery.

Sakai's [75] process obtained organic-inorganic core-shell beads. The aminopropyl silane's positively charged ammonium electrostatically bound to the alginate, after that the outer silanols attached the hydrolyzed TMOS to create the three-dimensional inorganic shell covering the calcium alginate center. The membrane shell permeability is being regulated by changing the molar ratio among TMOS and aminopropyl silane or increasing the shell thickness.

Silicates are known to avoid macrophage attraction, and following immersions in calcium-rich, and sodium alginate solutions the beads, would cover by the outer calcium alginate coating. Many inorganic-organic hybrid nanocomposites, consisting of indomethacin (IND), have been produced as a modeling drug by M. Catauro et al. [76] by utilizing inorganic (TEOS) and organic (polyethylene glycol, PEG) precursors through sol-gel technology. Indomethacin interaction with the inorganic material and its concentration appear to play a part in release kinetic models. In particular, it was found that the discs with the smallest dosage of indomethacin had a sigmoid-shaped release graph; the discs with the largest dosage of indomethacin (15 and10\% wt) had a time-dependent exponential drug release rate throughout the saline solution.

The incorporation of the polymer regulates the release of the drug in a different way. To achieve therapeutic techniques for utilization in iron deficiency anemia treatment, M. Catauro et al. [77] integrated various 


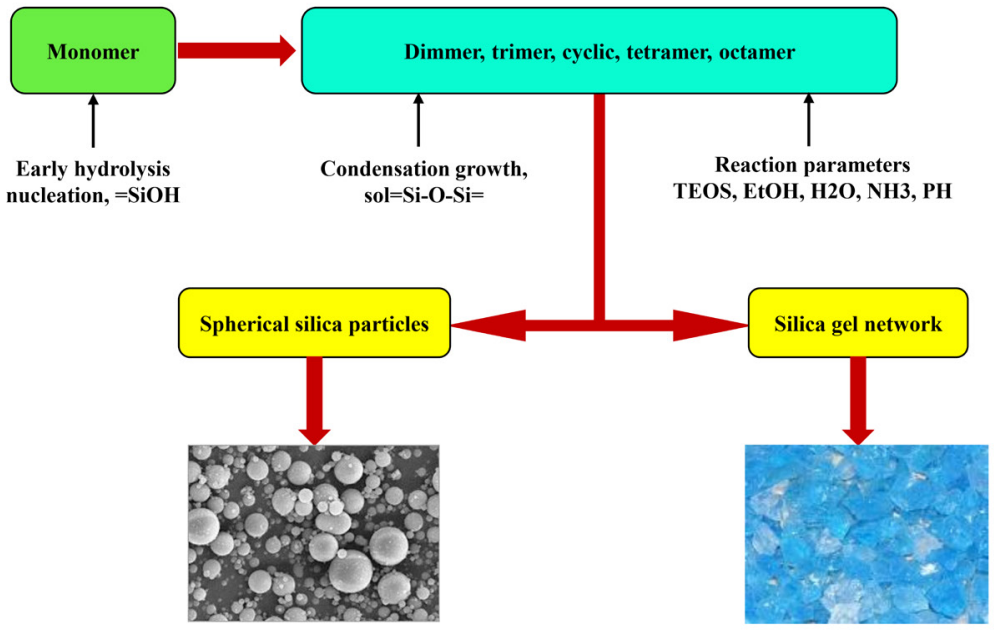

Fig. 4. Schematic of silica formation by the sol-gel process. quantities of pure $\mathrm{Fe}(\mathrm{II}) \mathrm{C}$ in $\mathrm{n}$ a silica matrix by a sol-gel method. The bioactivity analysis indicates that the existence of $\mathrm{Fe}(\mathrm{II}) \mathrm{C}$ does not influence the silica matrix's bioactivity. Hence, the obtained results promote the release kinetic assessment of $\mathrm{Fe}(\mathrm{II}) \mathrm{C}$ from $\mathrm{SiO}_{2} / \mathrm{Fe}$ (II)C hybrids to determine their possible application as drug delivery tools.

Cataura et al. [78] developed organic-inorganic hybrids based on chlorogenic acid/PEG using the sol-gel process in other experiments. The findings suggest that this biomaterial could be employed in multiple biomedical uses, including drug delivery, because of its flexibility and biocompatibility. Bollino et al. [79] produced organic hybrid (OIH) compounds for the regulated release of anti-inflammatory factors via the sol-gel system. The materials explored are $\mathrm{SiO}_{2}-\mathrm{PCL}$ OIH wherein ketoprofen $\left(\mathrm{SiO}_{2} / \mathrm{PCL} / \mathrm{KET}\right)$ or indomethacin $\left(\mathrm{SiO}_{2} / \mathrm{PCL} / \mathrm{IND}\right)$ is introduced. The findings demonstrate that the drug release relies on the amount of PCL and the drug molecule framework. Sol-gel polystyrene/ silica nanocomposites (PS/Si NCs) were produced by Mezan et al. [80]. The experimental result shows the potential for using $\mathrm{PS} / \mathrm{SiO}_{2}$ as coating, catalyst, and biomaterials such as drug carriers.

\subsection{Silica composite drug carriers}

Across multiple fields, including surface science and synthesis, the design of ceramic nanoparticles with enhanced characteristics has been investigated with remarkable progress. Silica, silicon carbide, titania, zirconia, alumina, silicon nitride are different ceramics types. Developments in nanotechnology have resulted in the advance of nanosized $\mathrm{SiO}_{2} \mathrm{a}$, which has been extensively utilized as a filler in composite engineering. Metal impurities are found in silica particles derived from natural sources and are not useful for advanced science and industrial purposes.

Synthetic silica (pyrogenic silica, precipitated silica, colloidal silica, and silica gels), which is refined and often manufactured in amorphous powder shapes, is therefore predominant in comparison with natural mineral $\mathrm{SiO}_{2}$ ( tridymite, quartz, cristobalite ) in the crystalline build. Reversed microemulsion, flame synthesis, and the sol-gel system are commonly employed techniques to generate silica nanoparticles. Due to its capability to regulate morphology, size distribution, and particle size by comprehensive control of process parameters, the sol-gel system is extensively employed to manufacture pure silica particles [81].

Modern medicine focuses on local therapy [82] and it is believed that employing silica composites in local drug distribution has some benefits including: (1) the capacity to integrate significant quantities of broadly scattered or dissolved drugs at low temperatures during solidification procedures, (2) the assurance of efficient stabilization of the drug load towards deterioration due to moderately well host-guest interactions, (3) the regulated kinetics of drug release by adjusting the porous silica structure characteristics. Medicinal drugs such as molsidomine [83], bisphosphonate [84], itraconazole [85], ibuprofen, doxorubicin (DOX) [86], and vancomycin [87] have also been integrated into silica compounds, providing many potentials for both regulated deliveries of medicines and effective local therapy [88].

Because of its capability to create pure and uniform materials under moderate conditions, the sol-gel system is commonly used to manufacture glass, ceramic, and silica materials for decades. The mechanism involves hydrolysis as well as metal alkoxides $\left(\mathrm{Si}(\mathrm{OR})_{4}\right)$ condensation including tetraethylorthosilicate (TEOS, $\left.\mathrm{Si}\left(\mathrm{OC}_{2} \mathrm{H}_{5}\right)_{4}\right)$ or inorganic salts including sodium silicate $\left(\mathrm{Na}_{2} \mathrm{SiO}_{3}\right)$ using as a catalyst in the presence of mineral base (e.g., $\mathrm{NH}_{3}$ ) or acid (e.g., $\mathrm{HCl}$ ) [89, 90]. In the sol-gel system, the fundamental interactions of TEOS that result in the forming of $\mathrm{SiO}_{2}$ particles can be formulated as $[39,91]$ :

$$
\begin{aligned}
& \mathrm{Si}\left(\mathrm{OC}_{2} \mathrm{H}_{5}\right)_{4}+\mathrm{H}_{2} \mathrm{O} \stackrel{\text { hydrolysis }}{\rightarrow} \mathrm{Si}\left(\mathrm{OC}_{2} \mathrm{H}_{5}\right)_{3} \mathrm{OH}+\mathrm{C}_{2} \mathrm{H}_{5} \mathrm{OH} \\
& \equiv \mathrm{Si}-\mathrm{O}-\mathrm{H}+\mathrm{H}-\mathrm{O}-\mathrm{Si} \equiv \stackrel{\text { water condensation }}{\rightarrow} \equiv \mathrm{Si}-\mathrm{O}-\mathrm{Si} \equiv+\mathrm{H}_{2} \mathrm{O} \\
& \equiv \mathrm{Si}-\mathrm{OC}_{2} \mathrm{H}_{5}+\mathrm{H}-\mathrm{O}-\mathrm{Si} \equiv \stackrel{\text { alcohol condensation }}{\rightarrow} \equiv \mathrm{Si}-\mathrm{O}-\mathrm{Si} \equiv+\mathrm{C}_{2} \mathrm{H}_{5} \mathrm{OH}
\end{aligned}
$$

Hydrolysis of the molecules of TEOS produces silanol groups. Siloxane bridges ( $\mathrm{Si}-\mathrm{O}-\mathrm{Si}$ ) forming the whole silica construct are formed by polymerization/condensation among the groups of silanol or the groups of silanol and ethoxy [81, 92]. It is possible to separate silica particle creation into two steps: (i) nucleation, (ii) growth. The two models, including monomer addition [93] and controlled aggregation [94], have been suggested to explain the silica growth process. The model of monomer addition shows that the particle growth happens after an initial nucleation burst by adding hydrolyzed monomers to the (primary) particles exterior. On the other hand, the model of aggregation describes that nucleation happens continuously during the process and that the resultant nuclei (primary particles) are aggregated together for the formation of dimmer, trimmer, and bigger particles (secondary particles). Based on the reaction parameters, illustrated in Fig. 4, both models contribute to creating either a gel network or spherical product [81].

The impact of hydroxy-terminated polydimethylsiloxane (PDMS) 
with $(10,20,30$, and 40 percent $(\mathrm{w} / \mathrm{w}))$ upon the physicochemical features of composites manufactured by low-temperature sol-gel polydimethylsiloxane/calcium phosphate/silica (PDMS-modified CaP/ $\mathrm{SiO}_{2}$ ) was described by Prokopowicz et al. [88]. The release study indicates that 20 percent PDMS in the composite was adequate to reduce the water-soluble molecule's burst release and resulted in zero-order drug release. This study suggests that the coefficient of drug partition and coefficient of permeability and its release did not alter with time.

An innovative warfarin-silica composite was designed by Parfenyuk et al. [95] for managed drug release using the sol-gel processing method. The kinetic parameters and release mechanisms for both drugs are identical in general. Nevertheless, unlike sol-gel molsidomine- $\mathrm{SiO}_{2}$ composites that displayed drug release kinetics near zero-order kinetics just in a strongly acidic medium, warfarin sol-gel composite with phenyl-modified $\mathrm{SiO}_{2}$ releases warfarin at roughly equal rates in the medium mimicking various sections of the gastrointestinal system according to zero-order kinetic law. The suggested warfarin-silica composite is a prospect for the continued processing of innovative oral warfarin $\mathrm{SiO}_{2}-$ based framework with regulated drug release. Stergar [96] presented a novel promising mechanism of drug delivery, that is, composites of Ni67.5Cu32.5 magnetic nanoparticles (MNPs) made by the sol-gel process. Using paracetamol (PCM), bupivacaine hydrochloride (BPC), and pentoxifylline (PTX) as model drugs, its ability to distribute drugs in a managed way was evaluated. $\mathrm{NiCu}$ particle release activity of PCM, BPC, and PTX verified that the base nanoparticles could release (and thus deliver) different drugs independent of their base characteristics.

Vlasenkova et al. [97] have developed a sol-gel/emulsion system to produce silica microcapsules to regulate release without losing their original form of the encapsulated protein. The processing parameters were observed to affect the unloaded silica particles' porous nature, the silica particle release qualities filled with bovine serum albumin (BSA), and encapsulated and released protein structural status significantly. Boffito et al. [98] suggested a different approach to this complex objective by mixing mesoporous $\mathrm{SiO}_{2}$ nanoparticles coated with a $\mathrm{pH}$ acid-sensitive self-immolating polymer (MSN-CS-SIP) with custom-made amphiphilic poly (ether urethane)s (PEUs) based thermo-sensitive hydrogels. The hybrid injectable compositions developed in this way could constitute a significant step in producing drug carriers that are responsive to multi-stimuli. These formulations can efficiently activate the release of their content appropriate to medical requirements by changing their behavior following biochemical signals from the surrounding physio-pathological setting.

\subsection{Calcium composite drug carriers}

Because of being potential candidates for decades of drug encapsulation and their biodegradability and biocompatibility, calcium-based nanostructured and calcium composites are extensively used in biomedicine $[99,100]$. Considering its broad uses for drug delivery and even tissue engineering, calcium carbonate, $\mathrm{CaCO}_{3}$, is currently one of the most described nanomaterials. This substance's appealing characteristic is that it stays slightly soluble in a neutral or basic medium but dissolves quickly in an acid medium, like cytosol $(\mathrm{pH}=5.5)$, allowing for selective release of uptake into the cells [101]

Kolanthai et al. [102] developed composite scaffolds of 3D porous calcium phosphate ((hydroxyapatite/ $\beta$-tricalcium phosphate)/agarose, (HAp/ $\beta$-TCP)/agarose) by sol-gel methodology with solvents of ethanol (EBS) and water (WBS). The growing bone could be supported by microporous scaffolds (WBS), while nanopores (EBS) could increase the degradation process. WBS and EBS could also be employed as scaffolds for drug delivery and tissue engineering. Palmqvist et al. [103] controlled nucleation and growth of produced nano by the sol-gel process to generate nanocomposites for drug delivery purposes by $\mathrm{CO}_{2}$ seques- tration by a calcium alkoxide solution. In neutral aqueous conditions, the composite particles are stable but are readily dissolved at $\mathrm{pH}=7.40$ in an acid media or also in phosphate-buffered saline (PBS), releasing the hydrophobic organic part in the form of a reasonably stable colloid solution. In both acidic and PBS media, successful ibuprofen release as a model drug was obtained and could be attenuated by including $\beta$-carotene as a hydrophobic portion.

In the endodontic materials design that facilitates regeneration of bone/cementum tissue and prevents bacterial growth, calcium silicate (CS)-based structures are useful. The mesoporous CS (MesoCS) nanocomposites were produced by Huang et al.[104] by employing sol-gel techniques. MesoCS nanoparticles could be used to retain the constant gentamicin release and fibroblast growth factor-2 as drug carriers (FGF2). Due to the release of FGF-2, the MesoCS-loaded FGF-2 can stimulate other odontogenic-related proteins than CS. In a study by Ghadiri et al. [105] in both acidic and alkaline media types, mesoporous calcium-magnesium-silicate was produced using the cetyltrimethylammonium bromide (CTAB)-assisted sol-gel process. The findings suggest that the reversal phase, the releasing of drug molecules, relies heavily on the surface area. The drug molecules have more accessible space during the diffusion stage to connect with specimens with larger surface area, facilitating more host-guest contact during the diffusion phase, thereby decreasing the release kinetics.

$\mathrm{CaP}$ as bioactive carriers produced in different kinds, such as thin coatings, ceramics, composites, and cement, appear to be an appropriate and widely used option in prosthesis for bone regeneration, [106]. The recent biphasic composites of mesoporous silica and calcium phosphate material $(\mathrm{CaP} @ \mathrm{MSi})$ in powder and pellet form were produced by Prokopowicz et al. [107] as a promising bone drug delivery method for doxycycline hydrochloride (DOX). The collected pellets retained CaP@ MSi permeability capacity and supported the sustained release of DOX for five days. The produced biphasic $\mathrm{CaP} @ \mathrm{MSi}$ composites tend to have the usage capacity of a bone-specific drug carrier. Szewczyk et al. [108] generated a MSi-CaP composite in the shape of spherical granules (pellets) filled with cefazolin as a model antibiotic. In comparison to the burst release of cefazolin-loaded MSi-CaP powders, the burst release of cefazolin from the pellets was decreased by 3 ( 90 and 30 percent after $15 \mathrm{~min}$ of release test, respectively). After 60 days of the mineralization potential assessment in the modeled body fluid, the experiments showed that the pellets' entire surface was coated with carbonated hydroxyapatite in line with the preferred morphology.

Through the sol-gel technique, Tsai et al. [109] developed mesoporous hydroxyapatite- $\mathrm{CaO}$ composite nanofibers ( $\mathrm{p}-\mathrm{HApFs}$ ) by utilizing Pluronic P123 as an electrospinning procedure and a porogen and discovered that $\mathrm{p}-\mathrm{HApFs}$ had sufficient drug loading capacity and could prolong the burst of tetracycline release (TC). A similar discovery relating to the creation of $\mathrm{CaO}$ in the synthesis of HAp by the sol-gel was also published by Lopatin et al. [110]. Nevertheless, several experiments have shown that the biocompatibility of HAp is adversely affected by $\mathrm{CaO}[111]$

Kanchana et al. [42] have shown that introducing strontium to biphasic calcium phosphate synthesis by the sol-gel process could reduce the forming $\mathrm{CaO}$ impurities. In this context, Tsai et al. [112] manufactured mesoporous composition strontium-substituted hydroxyapatite- $\mathrm{CaO}-\mathrm{CO}_{3}$ nanofibers (mSrHANFs) using an electrospinning system that relies on a sol-gel precursor with $\mathrm{CTAB}$ as porogen and assessed the impact of varying quantities of $\mathrm{Sr}$ doping on mSrHANF components. The mSrHANFs had a remarkable drug-loading capacity and could prolong TC burst release to sustain antibacterial function for over three weeks. Therefore, in bone tissue engineering, mSrHANFs could be used as drug carriers. The protein carrier was encapsulated by Purushothaman et al. [113], and casein was hybridized with superparamagnetic calcium ferrite nanoparticles (CFNP) (fabricated by the sol-gel technique) in 


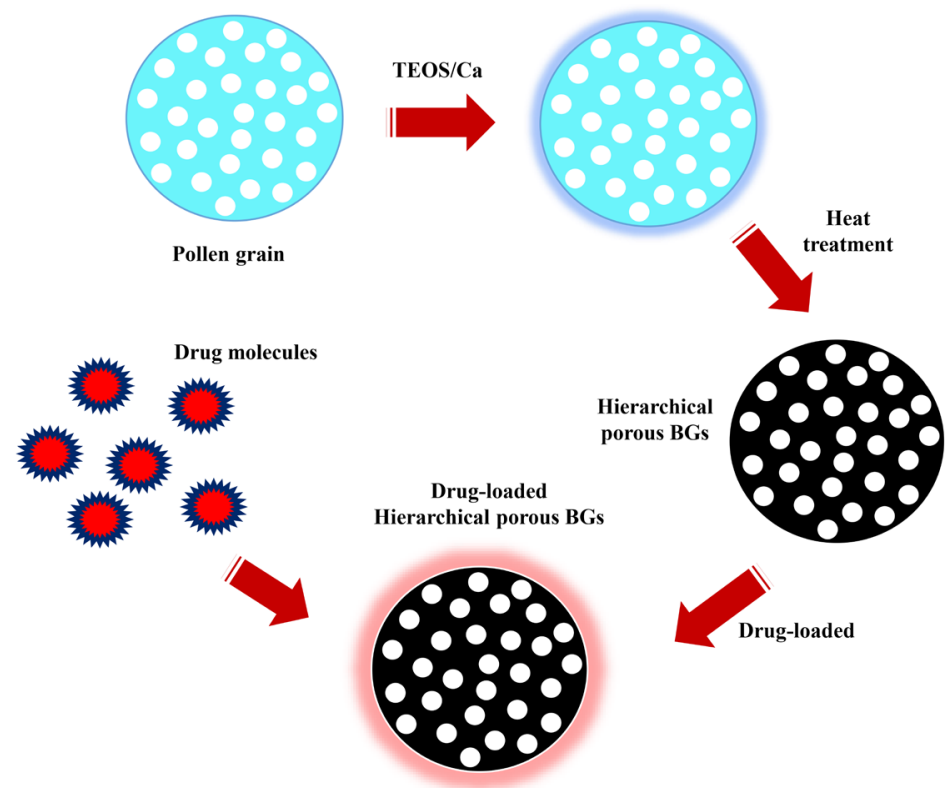

Fig. 5. Drug delivery systems based on porous BGs.

which the anti-cancer drug, curcumin (Cur), was included. Eventually, to make receptor-mediated endocytosis effective, folic acid (FA) was conjugated. In an acidic environment, elevated drug concentration, and magnetic field impact conditions, the drug release rate was higher. For casein-Cur with FA conjugation in contrast to the carrier lacking FA, the IC50 value decreased almost six-fold for MCF-7 cells. The caseinCFNP-Cur-FA was explicitly observed in the analysis as an innovative possible formulation for targeted drug delivery.

\subsection{Bioactive glass drug carriers}

Synthetic biomaterials of bioactive glasses (BGs) were first produced in the late 1960s [114] and they, by the apatite layer creation on their surface, are capable of binding to the bone. BGs are dissolvable under physiological conditions to various levels, being osteoinductive, osteoconductive, and angiogenic in specific compositions [115, 116]. These unique characteristics significantly enhance the BGs use in the regeneration/repair of bone [117].

Their potential has lately been illustrated in the field of soft tissue regeneration [118], with a focus on their biological activity to facilitate angiogenesis and to function as antibacterial agents. The biologically active ions release, stimulates specific healing mechanisms in soft tissue repair and wound healing [119], thus causes specific biological effects. BGs are amorphous in origin and have intermediate oxides, network modifiers, and network formers, in their framework [120]. Without external materials, the network designers could shape glasses independently [121].

$\mathrm{B}_{2} \mathrm{O}_{3}, \mathrm{SiO}_{2}, \mathrm{P}_{2} \mathrm{O}_{5}$ are the most studied network formers in BGs; network modifiers affect the glass structure by binding to non-bridging oxygen atoms such as $\mathrm{Si}-\mathrm{O}-\mathrm{M}+$ in which $\mathrm{M}+$ is a modifier cation; intermediate oxides could either perform as network modifiers or join the glass structure such as network formers [22]. $\mathrm{SiO}_{2}, \mathrm{P}_{2} \mathrm{O}_{5}$, and $\mathrm{B}_{2} \mathrm{O}_{3}$ could typically serve as network formers for generating BGs [122]. Nevertheless, regarding BGs generated by the sol-gel system, many of them are silicate glasses, and extensive research has focused on them since their emergence in the early 1990s [123]. By properly regulating the condensation and hydrolysis of borate precursors, borate BGs have lately been produced. The biological and physicochemical characteristics of BGs could be regulated by adjusting the composition [124]. Bioactive glass nanoparticles (BGN) are appealing biomaterials among the different morphologies of BGs for a significant variety of biomedical uses owing to their tiny scale, large surface-to-volume ratio, and high specific surface area that grant unique qualities to them [125].

Because of these desirable morphological features, in some uses, like drug delivery, BGN has significant benefits over its micron-sized counterparts. In general, BGNs are a good foundation for composites, as their morphological properties make their uniform integration into polymer matrices much simple [126, 127]. In addition, the use of structure-forming agents allows complicated morphologies including hollow or mesoporous structures to be accomplished by BGN. In effect, this improved porosity and surface area enhance BGN capacity to serve as drug carriers and other biomolecules for regulated release [128]. TEOS is the most commonly employed silicate precursor for the sol-gel production of BGN, whereas ethanol and/or water are used as solvents [129]. Under acidic or basic environments, the sol-gel process could occur, and those conditions influence the properties of the resulting materials. For instance, BGs with various morphologies could be accomplished by merely adjusting the solvent's $\mathrm{pH}$. TEOS initially precedes condensation and hydrolysis in the catalysts presence to form nanoparticles of $\mathrm{SiO}_{2}$ in a standard sol-gel procedure for BGN [130]. During the condensation and hydrolysis of TEOS or after the development of $\mathrm{SiO}_{2}$ nanoparticles, metal ion precursors could be included. To create BGN, the generated nanoparticles are then dried and calcinated. Organic substances could also be included during the production to form the particles or increase dispersity [129]. Moreover, to promote the processing of BGN [130], other methods, such as microemulsion [131], could be coupled with the sol-gel system. Drug delivery systems based on porous BGs are schematically presented in Fig. 5.

Wang et al. [132] effectively produced terbium-containing mesoporous bioactive glass nanospheres $(\mathrm{Tb} / \mathrm{MBG})$ by the sol-gel process. Findings have demonstrated that the developed nanospheres of Tb/MBG show excellent biocompatibility, rapid degradation, and regulated delivery of DOX. The release of DOX from nanospheres of Tb/MBG could be effectively adjusted by doping ion concentrations and modifying the pH condition. Hassanzadeh-Tabrizi et al. [133] have established an easy and efficient technique for preparing forsterite nanopowder via a surfactant-assisted sol-gel process as a novel drug delivery mechanism. During loading and releasing processes, ibuprofen molecules could be adsorbed onto mesoporous composites' surface in the impregnation phase and get released through diffusion-controlled mechanisms. The solvent reaches the ibuprofen-matrix phase via the pores during the release step. It could be shown that drug delivery is quicker in the early testing period reach- 
ing a slower pattern after around ten hours.

These findings are in line with the report by Horcajada et al. [134]. They studied the impact of MCM-41 pore size on drug delivery rate and demonstrated that the rate of ibuprofen delivery in a mimicking solution of body fluid declines as the pore size reduces. A composite formulated from hydroxyapatite forms MBG granules and bone cement, a promising carrier for biologically active proteins was investigated by Schumacher et al. [135]. Sol-gel technique was used, and mesoporous bioactive $\mathrm{CaO}-\mathrm{SiO}_{2}$ glass was produced. The feasibility of MBG particles to regulate the enzyme Lyz release and the growth factor VEGF from $\mathrm{CaP}$ cement (CPC) has been proven. Composites of $\mathrm{CPC} / \mathrm{MBG}$ appear to be a useful material for the growth factors delivery into bone fractures with a slightly improved porosity and mechanical strength that enhances over time. They could demonstrate that MBG improves and regulate the proteins release from the cement matrix.

Hollow mesoporous bioglass (HMBG) nanoparticles were produced by Wang et al. [136]. The HMBG nanoparticles had more significant potential for drug retention and stable drug release than the unique mesoporous architecture of HMBG. Furthermore, in vivo tests revealed that the nanoparticles of HMBG could facilitate regeneration of bone and the drug-loading nanoparticles of HMBG had a more remarkable ability to repair. Sayed et al. [137] examined hematite-doped chitosan/bioglass substrates as an alternate implant method to restore damaged root canals by delivering $2 \%$ chlorhexidine gluconate (CHX). As indicated by in vitro drug release and antibacterial experiments, the utilization of hematite $\left(\mathrm{Fe}_{2} \mathrm{O}_{3}\right)$ increased drug release and entirely removed bacterial growth within 14 days. A list of the composites produced by the sol-gel method is provided in Table 1 .

\section{In vitro and in vivo drug release studies}

It is possible to test the bioactivity of a composite and its specific components in vitro. Experiments are conducted by immersing specimens in SBF with a human plasma-like composition and ion concentration at $37{ }^{\circ} \mathrm{C}$ [146]. The in vitro approach for bioactivity analysis receives further appreciation due to concern for animal use in experiments. In vitro biodegradation of drug-releasing composites is investigated by detecting a decline in sample weight and molecular weight of the decaying polymer following immersion in a medium at $37^{\circ} \mathrm{C}$ over varying periods with liquids as a sterile solution of $\mathrm{pH} 7.4 \mathrm{PBS}$ [147] or simulated body fluid (SBF) [148] implementing as a condition of deterioration. While both liquids are not entirely appropriate for replicating the condition in vivo, SBF is a better option versus PBS. SBF simulates $\mathrm{pH}$ and ionic concentrations more precisely to plasma and supports the research sample with bioactivity. Therefore, when a composite is exposed to biodegradation tests, bioactivity will also be exhibited in SBF, and degradation will be affected, simulating better in vivo conditions. A composite's in vivo examination is not only limited to the release of drugs but also extended to its bioactivity $[149,150]$.

In vivo animal experiments are performed after radical debriding of localized osteomyelitis and estimating drug concentrations by collecting the drug from bone specimens. Commonly, in and near the places where the composites were in contact, the drug content was high, and the concentration reduced as the distance increased. Thus, there may be a strong need for organized administration of medications to protect the nearby bones and tissues under therapeutic circumstances of use, at least in the beginning for a limited duration. However, composites seem sufficiently appropriate and in their active state during the study period to release the drugs. It is not, however, a situation peculiar to composites. Drug delivery systems, either polymeric or inorganic, have identical conditions [151].

The mouse Langerhans islets encapsulation in sol-gel silicates was reported by Pope et al. [152] in 1997. In vitro experiments have shown that insulin could be produced and secreted by sol-gel encapsulated cells. In some diabetic mice, silica gel encapsulated islets have been transplanted inter-peritoneally and have been shown to lower their urinary sugar level significantly. These initial findings were promising since they proved that the sol-gel encapsulation offers a solution to overcome immune system rejection. Carturan et al. [153] resurrected this area of research systematically, beginning with conventional sol-gel procedures and later improving the Biosil gas phase deposition technique. They showed that by changing the silicate deposit's thickness or modifying its porosity, they could retain Langerhans cell viability in the silicates and regulate the barrier of mass transport.

Lately, the group has focused more on prosperous biohybrid transplantation in 10 glycemic rats. The results showed that $60 \%$ of the rats were alive after two months, but more significantly, their blood glucose level reduced from about $400 \mathrm{mg} / 1100 \mathrm{mg} / \mathrm{l}$ after transplantation. This trend remained for over a month at this level [154]. The authors reported that the encapsulation did not deteriorate the function of the islets. Moreover, Sakai et al. [155] showed that the inner alginate polymer could be liquefied by introducing citrate to chelate and remove the calcium binder. In another study by Sakai et al. [156], it was shown that the in vitro proliferation of pancreatic islets inside the siliceous pancreas was enabled by liquefication. The bioartificial pancreas capability to decrease and regulate the diabetic mice's blood glucose level from more than $400 \mathrm{mg} / \mathrm{l}$ to a healthy level of $200 \mathrm{mg} / \mathrm{l}$ for weeks was shown by in vivo experiments with diabetic mice.

Hu et al. [157] announced manufacturing of graphene oxide (GO)-integrated highly sensitive amphiphilic copolymer-based nanocomposite that displayed a low-intensity UV light-triggered sol-gel transformation. GO material could make the nucleation and unpleasant symptoms more apparent. An in vitro analysis examined the continuous drug release output of the hydrogel samples. The findings revealed that our drug carrier's release characteristics, namely the increased release rate within the acidic microenvironment of tumor conditions, are highly promising in improving patients with malignant tumors, cancer, and other diseases.

Dolinina et al. [134] have developed composites of molsidomine-silica. The $\mathrm{SiO}_{2}$ composites with the cardiovascular drug molsidomine were produced through sol-gel and adsorption in their research. In the in vitro study, the cumulative release rate of the drug was evaluated using the following expressions:

$\mathrm{V}$ is the complete release medium volume, $\mathrm{C}_{\mathrm{t}}$ is the drug concentration at time $t, C_{t-1}$ is the concentration of the drug at the time (t-1), $\mathrm{n}$ is the removed release medium volume, $\mathrm{w}$ is the drug content in the composite. As an instrumental error and sum of precision error, the relative variability in full release (percent) was not more than 4 percent. The findings achieved in this study show that the production process of composites of adsorption, molsidomine-silica, or sol-gel technology has a significant impact on the composites' release qualities. The composites have a variable drug distribution over the $\mathrm{SiO}_{2}$ matrixes and diverse durability of the composite structure in neutral media and acid due to different concepts of their creation.

Using sol-gel processing, Kolanthai et al. [158] developed nanosized $\left(80 \times 23 \mathrm{~nm}^{2}\right)$ and porous $(17 \pm 1 \mathrm{~nm}) \mathrm{HAp} /$ agarose composite rods. The composite exhibited an initial burst release of around 60 percent within ten hours regarding in vitro drug release. The regulated release of drugs was subsequently reported. A strong interaction of the HAp mesoporous surface with the drug was associated with sustained release. Finally, for reconstructive surgery uses, bone filling, and drug delivery, the composite powder could be used. A smart $\mathrm{pH}$-responsive nano-carrier (P.4-VP@MCM-41) by utilizing P.4-VP as reversible pH-sensitive gatekeepers and MCM-41 as drug nano-containers has been effectively developed by Abbaszad Rafi et al. [159]. The polymerizable functional groups (3-(Trimethoxysilyl)propylmethacrylate) were mostly grafted 
Table 1.

Composites Studied for Drug Delivery via sol-gel method

\begin{tabular}{|c|c|c|c|c|c|}
\hline Carrier & Cytotoxicity behavior of carrier & Drug & Experimental medium & Drug release behavior & Reference \\
\hline $\begin{array}{l}\text { Bioactive glass } \\
\text { ceramics }\end{array}$ & - & Gentamicin & PBS & $\begin{array}{l}\text { The drug release outcome exhibited that } \\
\text { both } 45 \mathrm{~S} 5 \text { and } \mathrm{S} 53 \mathrm{P} 4 \text { showed a gradually } \\
\text { continuous gentamicin release. }\end{array}$ & $\begin{array}{c}\text { Auniq et al. } \\
\quad[134]\end{array}$ \\
\hline $\begin{array}{l}\text { Calcium ferrite } \\
\text { nanoparticles } \\
(\mathrm{CFNP})\end{array}$ & $\begin{array}{c}\text { Cytotoxicity test performed MCF-7 } \\
\text { breast cancer cells, and results showed } \\
\text { The IC50 value reduced nearly six-fold } \\
\text { for MCF-7 cells }\end{array}$ & Curcumin & $\begin{array}{l}\text { Acidic conditions and } \\
\text { under the influence of } \\
\text { magnetic field }\end{array}$ & $\begin{array}{l}\text { The drug release rate was higher in acidic } \\
\text { conditions, increased drug concentrations, } \\
\text { and under the influence of the magnetic } \\
\text { field. }\end{array}$ & $\begin{array}{l}\text { Purushothaman } \\
\text { et al. [109] }\end{array}$ \\
\hline $\begin{array}{l}\text { Magnetite }\left(\mathrm{Fe}_{3} \mathrm{O}_{4}\right)- \\
\text { doped nanoparticles } \\
\text { of mesoporous } \\
\text { bioactive glass } \\
\left(\mathrm{Fe}_{3} \mathrm{O}_{4} \text {-MBG NPs) }\right.\end{array}$ & $\begin{array}{c}\text { No considerable normal human } \\
\text { fibroblast (NHFB) cell death was } \\
\text { detected during in vitro analysis. For } \\
\text { nanoparticles of } \mathrm{Mc}_{-} \mathrm{Fe}_{3} \mathrm{O}_{4}-\mathrm{MBG} \\
\text { significant inhibitory influences on the } \\
\text { cancer cells (MG-63) viability were } \\
\text { observed. }\end{array}$ & Mitomycin & SBF & $\begin{array}{l}\text { Nanoparticles of } \mathrm{Fe}_{3} \mathrm{O}_{4}-\mathrm{MBG} \text { expressed } \\
\text { low cytotoxicity, good biocompatibility, and } \\
\text { controlled release thus, for drug delivery, } \\
\text { they are a safe biomaterial. }\end{array}$ & $\begin{array}{c}\text { Rahman et al. } \\
\text { [135] }\end{array}$ \\
\hline $\mathrm{Ag}_{2} \mathrm{O}-\mathrm{MBG} \mathrm{NPs}$ & $\begin{array}{c}\text { At } 11.88 \mu \mathrm{g} / \mathrm{mL} \text { of nanoparticles } \\
\text { of DOX- } \mathrm{Ag}_{2} \mathrm{O}-\mathrm{MBG} \text {, significant } \\
\text { inhibitory influence on the viability of } \\
\text { the MG- } 63 \text { osteosarcoma cancer cells } \\
\text { was detected. }\end{array}$ & DOX & SBF & $\begin{array}{l}\text { Doxorubicin (DOX) was encapsulated with } \\
84 \% \text { efficiency. The release of DOX was } \\
\text { affected by release media } \mathrm{pH}(6.4-8.4) \text { and } \\
\text { the drug loading concentration }(0.2-1.0 \mathrm{mg} / \\
\mathrm{mL}) \text {. DOX release was } 93 \% \text { was witnessed } \\
\text { almost for two weeks at a little acidic } 6.4 \\
\mathrm{pH} \text {. }\end{array}$ & $\begin{array}{c}\text { Rahman et al. } \\
\text { [136] }\end{array}$ \\
\hline $\begin{array}{c}\mathrm{SiO}_{2} / \mathrm{PCL} \mathrm{OIHs} \\
\text { (organic-inorganic) }\end{array}$ & $\begin{array}{l}\text { The compatibility with the organic } \\
\text { solvent, the starting liquid state, and } \\
\text { the slow processing temperatures } \\
\text { make the sol-gel an ideal method to } \\
\text { synthesize OIHs. }\end{array}$ & $\begin{array}{l}\text { Anti-inflam- } \\
\text { matory IND } \\
\text { or KET }\end{array}$ & SBF & $\begin{array}{l}\text { The IND speed release reduces with increas- } \\
\text { ing PCL the wt } \% \text {, whereas the speed release } \\
\text { of KET increases with PCL increasing of } \\
\text { wt } \% \text {. }\end{array}$ & $\begin{array}{l}\text { Bollino et al. } \\
\qquad[75]\end{array}$ \\
\hline $\begin{array}{l}\text { Terbium doped mes- } \\
\text { oporous bioactive } \\
\text { glasses }(\mathrm{Tb} / \mathrm{MBG})\end{array}$ & $\begin{array}{l}\text { The } \mathrm{Tb} / \mathrm{MBG} \text { cytotoxicity assessed } \\
\text { by a cell counting kit- } 8 \text { (CCK-8), and } \\
\text { results revealed that the carrier at low } \\
\text { concentration had no notable cytotox- } \\
\text { icity in MC3T3 cells. }\end{array}$ & DOX & SBF & $\begin{array}{l}\text { Nanospheres of Tb/MBG exhibited con- } \\
\text { trolled release property of anti-cancer drugs } \\
\text { (DOX) and distinct degradation in PBS with } \\
\text { various pH values. Their mechanism of re- } \\
\text { lease can be described by Fickian diffusion } \\
\text { according to the model of Higuchi. }\end{array}$ & $\begin{array}{l}\text { Wang et al. } \\
\text { [128] }\end{array}$ \\
\hline $\begin{array}{l}\text { Polymethyl methyl } \\
\text { acrylate/polystyrene/ } \\
\text { silica composite }\end{array}$ & $\begin{array}{l}\text { The cytotoxicity studies by RAW } \\
\text { macrophage cells exhibited that all the } \\
\text { samples showed good cell viability. }\end{array}$ & $\begin{array}{l}\text { 5-Fluoro- } \\
\text { uracil }\end{array}$ & PBS & $\begin{array}{l}\text { The kinetics of drug release showed that the } \\
\text { drug was released in a sustained manner for } \\
\text { a period of } 180 \mathrm{~h} \text { in PBS at a pH of } 6.8 .\end{array}$ & $\begin{array}{l}\text { Shanmugasund- } \\
\text { ar et al. [137] }\end{array}$ \\
\hline $\begin{array}{c}\text { Silica-calcium } \\
\text { phosphate composite } \\
\text { (MSi-CaP) }\end{array}$ & - & Cefazolin & SBF & $\begin{array}{l}\text { The burst release of cefazolin from the } \\
\text { pellets was reduced by } 3 \text { when compared to } \\
\text { the burst release of cefazolin-loaded MSi- } \\
\text { CaP powders ( } 90 \text { and } 30 \% \text { after } 15 \text { min of } \\
\text { release studies, respectively). }\end{array}$ & $\begin{array}{c}\text { Szewczyk et al. } \\
{[104]}\end{array}$ \\
\hline HMBG & $\begin{array}{c}\text { Nanoparticles had good biocompatibil- } \\
\text { ity and they could promote MG- } 63 \text { cell } \\
\text { proliferation considerably. }\end{array}$ & Ibuprofen & SBF & $\begin{array}{l}\text { MBG nanoparticles had sustained drug } \\
\text { release ability and higher drug loading due } \\
\text { to their special hollow structure and penetra- } \\
\text { tive mesopores on the shell. }\end{array}$ & $\begin{array}{l}\text { Wang et al. } \\
\text { [138] }\end{array}$ \\
\hline $\left.\mathrm{Ca}_{3} \mathrm{Mg}\left(\mathrm{SiO}_{4}\right)_{2}\right)$ & $\begin{array}{l}\text { The cytocompatibility, mechanical } \\
\text { properties, and bioactivity of the } \\
\text { compound have been comprehensively } \\
\text { assessed. }\end{array}$ & Ibuprofen & SBF & $\begin{array}{l}\text { The synthesized calcium-magnesium-sili- } \\
\text { cate samples' potential application as a drug } \\
\text { delivery agent is investigated by estimating } \\
\text { the ibuprofen release properties of them up } \\
\text { to } 180 \mathrm{~h} \text {. }\end{array}$ & $\begin{array}{l}\text { Bigham et al. } \\
\text { [139] }\end{array}$ \\
\hline $\begin{array}{l}\text { MBG/polyurethanes } \\
\text { (PUs) nanocom- } \\
\text { posite }\end{array}$ & $\begin{array}{c}\text { The nanocomposites showed high } \\
\text { cell viability (96-100\%) and are thus } \\
\text { designated as biocompatible. }\end{array}$ & Imatinib & SBF & $\begin{array}{l}\text { There was no burst influence and } 52-84 \% \\
\text { of the drug was released during } 3 \text { weeks }\end{array}$ & $\begin{array}{l}\text { Shoaib et al. } \\
\quad[140]\end{array}$ \\
\hline $\begin{array}{l}\text { Samarium incorpo- } \\
\text { rated mesoporous } \\
\text { bioactive glasses } \\
\quad(\mathrm{Sm} / \mathrm{MBG})\end{array}$ & - & DOX & SBF & $\begin{array}{l}\text { The results exhibited that the Sm/MBG/ } \\
\text { alginate microspheres show sustained DOX } \\
\text { delivery, and their mechanism of release is } \\
\text { controlled by Fickian diffusion according to } \\
\text { the model of Higuchi. }\end{array}$ & $\begin{array}{l}\text { Zhang et al. } \\
\quad[141]\end{array}$ \\
\hline
\end{tabular}


onto MCM-41 pore entrants to provide the silica-based nano-container following MSNs synthesis through the surfactant-assisted sol-gel system, with no surfactant removal. The release of the drug could be limited at $\mathrm{pH} 7.4$ in the bloodstream based on the current in vitro results; nevertheless, due to the cancerous cell acidic microenvironment, an accelerated release would be found in cancerous tissues. Accordingly, this nano-carrier could have a possible use for anti-cancer drugs in $\mathrm{pH}$-sensitive delivery systems.

A new technique was applied by Ghazaiea [160] to monitor various drug releases by encapsulating them using sol-gel in organic-inorganic hybrids. By utilizing UV-visible spectrophotometry (UV-Vis), the drug release of the composites of $\mathrm{N}$-triethylchitosan/sodium naproxen@ $\mathrm{SiO}_{2}$ was examined. At a physiological temperature of $37^{\circ} \mathrm{C}$ and a $\mathrm{pH}$ of 7.4, this research was carried out. This sort of sol-gel process could develop composites of different sizes and porous shells. Dynamic light scattering (DLS) and zeta potential analysis results indicate that particles of various sizes and shapes are possible. Kumaresan's [161] synthetic saponite has been effectively produced using the sol-gel hydrothermal process and Quinine (QU) as a guest molecule. During controlled release experiments, they also compared the natural (NSAP) and synthetic (SSAP) saponite clay with QU nanocomposite and pure QU. Normal QU and drug-loaded QNSAP and QSSAP nanocomposite in vitro drug release experiments have been successfully performed by employing dialysis bag procedure using the $\mathrm{pH}$ gradient process in the physiological setting. The study proved that the SSAP presented better-controlled release patterns than NSAP and pure QU. The current result also shows that the natural/synthetic saponite clay minerals are more efficient materials to be employed as simplistic and effective drug release vehicles.

An innovative biodegradable thermosensitive composite hydrogel based on PEG-PCL-PEG (PECE) and Pluronic F127 copolymer undergoing thermosensitive sol-gel transformation was produced by Gong et al. [162]. The composite hydrogel cytotoxicity was tested through utilizing human HEK293 cells through a cell viability method. The viability of 293 cells in the presence of composite hydrogel copolymers, even though the input copolymers was $500 \mu \mathrm{g}$ per well, was still greater than 71.4 percent. The sample drugs used were BSA, vitamin B12 (VB12), honokiol (HK) to study the in vitro release activity of protein drugs, hydrophilic small molecular drugs, hydrophobic small molecular drugs, and the composite hydrogel. The higher Pluronic F127 quantity, lower concentration of hydrogel, or less initial drug loading led to a higher cumulative rate of release.

Kundu et al. [163] produced a novel localized drug delivery method focused on drug-loaded porous hydroxyapatite ceftriaxone-sulbactam composite. It was found that the lower percentage of pores with a range of mostly micro-pores was better than the higher percentage of pores both in vitro and in vivo. CFS (combination of b-lactam antibiotic and b-lactamase inhibitor) release from HAp prosthetics was quicker than $\mathrm{SBF}$ in PBS. Besides, both in vivo and in vitro drug elution findings after six weeks revealed that the CFS release against Staphylococcus aureus was more significant than the minimum inhibitory dosage. The advantages of CFS loaded HAp implants over the parenteral group are on pathogen elimination and new bone development, which was also shown in-vivo experiments.

Safari et al.[164] synthesized dopamine (DOP)/chitosan (CIS)@ $\mathrm{TiO}_{2}$ nanohybrid composites by the sol-gel process. In comparison to the DOP/CIS composites, $\mathrm{TiO}_{2}$ integration significantly increased drug trapping and decreased drug release. After $10 \mathrm{~min}$ in a $\mathrm{pH} 7.4$ solution, the DOP/CIS composites lacking $\mathrm{TiO}_{2}$ coating released the entire drug, whereas the $\mathrm{TiO}_{2}$ coated composites released the trapped drug after $16 \mathrm{~h}$. The effects are quite promising and could be used to adjust DOP usage from injection to oral. Rahman et al. [81] doped nanoparticles of silver oxide mesoporous bioactive glass $\left(\mathrm{Ag}_{2} \mathrm{O}-\mathrm{MBG} \mathrm{NPs}\right)$ for the regulated doxorubicin release as a model drug by the sol-gel process.
Through MTT assay and in vivo tissue histopathology, the as-synthesized nanoparticles of $\mathrm{Ag}_{2} \mathrm{O}-\mathrm{MBG}$ did not present any adverse impact, and drug release was regulated by adjusting the $\mathrm{pH}$ of the released medium, and dosage of drug loading. These properties have shown that the $\mathrm{Ag}_{2} \mathrm{O}-\mathrm{MBG}$ NPs method is beneficial for the bone cancer medication of bone tissue regeneration.

\section{Conclusions and future insight}

Lately, given the simplicity and usefulness of sol-gel approaches in regulating the structure and characteristics of BGN, sol-gel production of BGN has been gradually studied. Because of their qualities, BGN can be great transporters of drugs. Even though impressive improvement has been accomplished in the manufacturing of BGN, many other challenges remain, particularly regarding the accurate control of composition and size that must be addressed to achieve efficient BGN usage. By changing production parameters, including catalyst concentration and TEOS, the BGN size may be easily adjusted, but smaller particles are prone to aggregate to shape larger clusters, particularly in the salts presence. This restriction complicates the development of highly scattered BGN smaller than $100 \mathrm{~nm}$. The critical challenge found by a variety of research is that the inclusion of metallic salts usually causes nanoparticles to be aggregated. On the other hand, in drug delivery, organic-inorganic composites and porous inorganic materials, including calcium carbonates, mesoporous silica, calcium phosphates, and other silica and calcium-based structures, have been commonly used as carriers. Such carriers can also be produced using the sol-gel process. These technologies have several qualities, such as high bioactive drug loading, in vivo navigating and visualization, and remote content release by internal and external stimuli.

The morphological and surface qualities of silica and calcium configurations enable organic functionalization to be carried out to innovative and effective hybrid carriers with improved multimodal characteristics being created. In addition, there are several options for co-encapsulating of different bioactive compounds in situ (fluorescent molecule, drug, protein, and gene). These products, however, can also have some limitations related to their stability and safety. While these materials are known to be non-toxic, it is always necessary to monitor and control the concentration of particles utilized to prevent harmful impacts. Further considerations relating to particle stability should be addressed when dealing with biological fluids (blood plasma, cell culture media). For example, in biological fluids, organic compounds appear to bind to drug carriers' surface, creating so-called coronas across the particles. This corona could modify the physicochemical characteristics of particles dramatically, leading to the aggregation of particles. They should therefore be characterized not only in aqueous solutions, but also in biological fluids. More studies on the design of these comparatively high capacity carriers seem to be essential to minimize the shortcomings of each as much as possible.

\section{REFERENCES}

[1] G. Gregoriadis, Targeting of drugs, Nature 265(5593) (1977) 407-411.

[2] A. Zaffaroni, Therapeutic systems: the key to rational drug therapy, Drug metabolism reviews 8(2) (1978) 191-221.

[3] M. Hashida, Role of pharmacokinetic consideration for the development of drug delivery systems: A historical overview, Advanced drug delivery reviews (2020).

[4] H. Bundgaard, M. Johansen, Pro-drugs as drug delivery systems XX. Oxazolidines as potential pro-drug types for $\beta$-aminoalcohols, aldehydes or ketones, International Journal of Pharmaceutics 10(2) (1982) 165-175.

[5] B.B. Patel, N.A. Patel, Brain targeting drug delivery system through nasal cavity, Pharma News (2021).

[6] L. Li, Y. He, X. Zheng, L. Yi, W. Nian, Progress on Preparation of pH/Temperature-Sensitive Intelligent Hydrogels and Applications in Target Transport and Con- 
trolled Release of Drugs, International Journal of Polymer Science 2021 (2021). [7] J. Zhuang, L. Zhou, W. Tang, T. Ma, H. Li, X. Wang, C. Chen, P. Wang, Tumor targeting antibody-conjugated nanocarrier with $\mathrm{pH} /$ thermo dual-responsive macromolecular film layer for enhanced cancer chemotherapy, Materials Science and Engineering: C 118 (2021) 111361.

[8] N.T.T. Le, D.T.D. Nguyen, N.H. Nguyen, C.K. Nguyen, D.H. Nguyen, Methoxy polyethylene glycol-cholesterol modified soy lecithin liposomes for poorly water-soluble anticancer drug delivery, Journal of Applied Polymer Science 138(7) (2021) 49858

[9] M. Abniki, A. Moghimi, F. Azizinejad, Fabrication of bionanocomposite based on LDH using biopolymer of gum arabic and chitosan-coating for sustained drug-release, Journal of the Serbian Chemical Society 85(9) (2020) 1223-1235. [10] J. Daraei, Production and characterization of PCL (Polycaprolactone) coated $\mathrm{TCP} /$ nanoBG composite scaffolds by sponge foam method for orthopedic applications, Journal of Composites and Compounds 2(2) (2020) 44-49.

[11] E. Asadi, A.F. Chimeh, S. Hosseini, S. Rahimi, B. Sarkhosh, L. Bazli, R. Bashiri, A.H.V. Tahmorsati, A review of clinical applications of graphene quantum dot-based composites, Journal of Composites and Compounds 1(1) (2019) 31-40. [12] H.W. Jang, A. Zareidoost, M. Moradi, A. Abuchenari, A. Bakhtiari, R. Pouriamanesh, B. Malekpouri, A.J. Rad, D. Rahban, Photosensitive nanocomposites: environmental and biological applications, Journal of Composites and Compounds 2(2) (2020) 50-60.

[13] Y. Zamania, A. Zareeinb, L. Bazlic, R. NasrAzadanid, B.P. Mahammode, S. Nasibi, A.M. Chahardehig, Journal of Composites and Compounds, (2020).

[14] Y. Zamani, A. Zareein, L. Bazli, R. Nasr Azadani, B.P. Mahammod, S. Nasibi, A.M. Chahardehi, Nanodiamond-containing composites for tissue scaffolds and surgical implants: A review, Journal of Composites and Compounds 2(5) (2020) 215-227.

[15] A. Czajkowska-Kośnik, M. Szekalska, K. Winnicka, Nanostructured lipid carriers: A potential use for skin drug delivery systems, Pharmacological Reports 71(1) (2019) 156-166.

[16] F. Niazvand, A. Cheshmi, M. Zand, R. NasrAzadani, B. Kumari, A. Raza, S. Nasibi, An overview of the development of composites containing Mg and $\mathrm{Zn}$ for drug delivery, Journal of Composites and Compounds 2(5) (2020) 193-204.

[17] M. Abniki, A. Moghimi, F. Azizinejad, Synthesis of calcium-layered double hydroxide based nanohybrid for controlled release of an anti-inflammatory drug, Journal of the Chinese Chemical Society (2020).

[18] C. Tipa, M.T. Cidade, T. Vieira, J.C. Silva, P.I. Soares, J.P. Borges, A New Long-Term Composite Drug Delivery System Based on Thermo-Responsive Hydrogel and Nanoclay, Nanomaterials 11(1) (2021) 25.

[19] A. Moghanian, A. Ghorbanoghli, M. Kazem-Rostami, A. Pazhouheshgar, E. Salari, M. Saghafi Yazdi, T. Alimardani, H. Jahani, F. Sharifian Jazi, M. Tahriri, Novel antibacterial $\mathrm{Cu} / \mathrm{Mg}$-substituted 58S-bioglass: Synthesis, characterization and investigation of in vitro bioactivity, International Journal of Applied Glass Science 11(4) (2020) 685-698

[20] M.S.N. Shahrbabak, F. Sharifianjazi, D. Rahban, A. Salimi, A comparative investigation on bioactivity and antibacterial properties of sol-gel derived $58 \mathrm{~S}$ bioactive glass substituted by Ag and Zn, Silicon 11(6) (2019) 2741-2751.

[21] A. Esmaeilkhanian, F. Sharifianjazi, A. Abouchenari, A. Rouhani, N. Parvin, M. Irani, Synthesis and characterization of natural nano-hydroxyapatite derived from turkey femur-bone waste, Applied biochemistry and biotechnology 189(3) (2019) 919-932.

[22] L. Bazli, B. Eftekhari Yekta, A. Khavandi, Preparation and Characterization of Sn-Containing Glasses for Brachytherapy Applications, Transactions of the Indian Ceramic Society 76(4) (2017) 242-246.

[23] Q. Lei, J. Guo, A. Noureddine, A. Wang, S. Wuttke, C.J. Brinker, W. Zhu, Sol-Gel-Based Advanced Porous Silica Materials for Biomedical Applications, Advanced Functional Materials 30(41) (2020) 1909539.

[24] K. Unger, H. Rupprecht, B. Valentin, W. Kircher, The use of porous and surface modified silicas as drug delivery and stabilizing agents, Drug Development and Industrial Pharmacy 9(1-2) (1983) 69-91.

[25] P.P. Nampi, V.S. Mohan, A.K. Sinha, H. Varma, High surface area sol-gel nano silica as a novel drug carrier substrate for sustained drug release, Materials Research Bulletin 47(6) (2012) 1379-1384

[26] A. Rajaeiyan, M. Bagheri-Mohagheghi, Comparison of sol-gel and co-precipitation methods on the structural properties and phase transformation of $\gamma$ and $\alpha-\mathrm{Al}$ 2 O 3 nanoparticles, Advances in Manufacturing 1(2) (2013) 176-182.

[27] V.S. Rizi, F. Sharifianjazi, H. Jafarikhorami, N. Parvin, L.S. Fard, M. Irani, A. Esmaeilkhanian, Sol-gel derived $\mathrm{SnO}_{2} / \mathrm{Ag}_{2} \mathrm{O}$ ceramic nanocomposite for $\mathrm{H}_{2}$ gas sensing applications, Materials Research Express 6(11) (2019) 1150g2.

[28] F. Sharifianjazi, M. Moradi, A. Abouchenari, A.H. Pakseresht, A. Esmaeilkhanian, M. Shokouhimehr, M.S. Asl, Effects of Sr and Mg dopants on biological and mechanical properties of $\mathrm{SiO}_{2}-\mathrm{CaO}-\mathrm{P}_{2} \mathrm{O}_{5}$ bioactive glass, Ceramics International 46(14) (2020) 22674-22682.

[29] F. Sharifianjazi, M. Moradi, N. Parvin, A. Nemati, A.J. Rad, N. Sheysi, A. Abouchenari, A. Mohammadi, S. Karbasi, Z. Ahmadi, Magnetic $\mathrm{CoFe}_{2} \mathrm{O}_{4}$ nanoparticles doped with metal ions: a review, Ceramics International (2020).

[30] L. Bazli, M. Siavashi, A. Shiravi, A review of carbon nanotube $/ \mathrm{TiO}_{2}$ composite prepared via sol-gel method, Journal of Composites and Compounds 1(1) (2019)

[31] M.A. Zadeh, S. Van Der Zwaag, S. Garcia, Routes to extrinsic and intrinsic self-healing corrosion protective sol-gel coatings: a review, Self-Healing Materials 1 (2013) 1-18.

[32] M. Catauro, E. Tranquillo, R. Risoluti, S. Vecchio Ciprioti, Sol-Gel synthesis, spectroscopic and thermal behavior study of $\mathrm{SiO}_{2} / \mathrm{PEG}$ composites containing different amount of chlorogenic acid, Polymers 10(6) (2018) 682

[33] T. Graham, XXXV.- On the properties of silicic acid and other analogous colloidal substances, Journal of the Chemical Society 17 (1864) 318-327.

[34] J.D. Wright, N.A. Sommerdijk, Sol-gel materials: chemistry and applications, CRC press 2000

[35] Ebelmen, Recherches sur les combinaisons des acides borique et silicique avec les éthers, 1846.

[36] W.A. Patrick, Silica gel and process of making same, Google Patents, 1919.

[37] S.S. Kistler, Coherent expanded aerogels and jellies, Nature 127(3211) (1931) 741-741.

[38] G.J. Owens, R.K. Singh, F. Foroutan, M. Alqaysi, C.-M. Han, C. Mahapatra, H.-W. Kim, J.C. Knowles, Sol-gel based materials for biomedical applications, Progress in Materials Science 77 (2016) 1-79.

[39] L.L. Hench, J.K. West, The sol-gel process, Chemical Reviews 90(1) (1990) 33-72.

[40] D. Wang, G.P. Bierwagen, Sol-gel coatings on metals for corrosion protection, Progress in organic coatings 64(4) (2009) 327-338.

[41] A.R. Rouhani, A.H. Esmaeil-Khanian, F. Davar, S. Hasani, The effect of agarose content on the morphology, phase evolution, and magnetic properties of $\mathrm{CoFe}_{2} \mathrm{O}_{4}$ nanoparticles prepared by sol-gel autocombustion method, International Journal of Applied Ceramic Technology 15(3) (2018) 758-765.

[42] B. Riegel, S. Blittersdorf, W. Kiefer, S. Hofacker, M. Müller, G. Schottner, Kinetic investigations of hydrolysis and condensation of the glycidoxypropyltrimethoxysilane/aminopropyltriethoxy-silane system by means of FT-Raman spectroscopy I, Journal of non-crystalline solids 226(1-2) (1998) 76-84.

[43] C. Brinker, K. Keefer, D. Schaefer, C. Ashley, Sol-gel transition in simple silicates, Journal of Non-Crystalline Solids 48(1) (1982) 47-64

[44] N. Job, R. Pirard, J. Marien, J.-P. Pirard, Porous carbon xerogels with texture tailored by pH control during sol-gel process, Carbon 42(3) (2004) 619-628.

[45] S. Askari, M. Ghashang, G. Sohrabi, Synthesis and mechanical properties of $\mathrm{Bi}_{2} \mathrm{O}_{3}-\mathrm{Al}_{4} \mathrm{Bi}_{2} \mathrm{O}_{9}$ nanopowders, Journal of Composites and Compounds 2(5) (2020). [46] G.W. Scherer, C.J. Brinker, E.P. Roth, Sol $\rightarrow$ gel $\rightarrow$ glass: III. Viscous sintering, Journal of non-crystalline solids 72(2-3) (1985) 369-389.

[47] L. Ding, X. Zhu, Y. Wang, B. Shi, X. Ling, H. Chen, W. Nan, A. Barrett, Z. Guo, W. Tao, J. Wu, X. Shi, Intracellular Fate of Nanoparticles with Polydopamine Surface Engineering and a Novel Strategy for Exocytosis-Inhibiting, Lysosome Impairment-Based Cancer Therapy, Nano Letters 17(11) (2017) 6790-6801.

[48] X. Zhu, X. Ji, N. Kong, Y. Chen, M. Mahmoudi, X. Xu, L. Ding, W. Tao, T. Cai, Y. Li, T. Gan, A. Barrett, Z. Bharwani, H. Chen, O.C. Farokhzad, Intracellular Mechanistic Understanding of 2D MoS 2 Nanosheets for Anti-Exocytosis-Enhanced Synergistic Cancer Therapy, ACS Nano 12(3) (2018) 2922-2938.

[49] Y.V. Solovev, A.Y. Prilepskii, E.F. Krivoshapkina, A.F. Fakhardo, E.A. Bryushkova, P.A. Kalikina, E.I. Koshel, V.V. Vinogradov, Sol-gel derived boehmite nanostructures is a versatile nanoplatform for biomedical applications, Scientific Reports 9(1) (2019) 1176

[50] B. Ben-Nissan, A.H. Choi, Sol-gel production of bioactive nanocoatings for medical applications. Part 1: an introduction, Nanomedicine 1(3) (2006) 311-319. [51] Q. Lei, J. Guo, A. Noureddine, A. Wang, S. Wuttke, C.J. Brinker, W. Zhu, Sol-Gel-Based Advanced Porous Silica Materials for Biomedical Applications, Advanced Functional Materials 30(41) (2020) 1909539

[52] F. Sharifianjazi, A. Esmaeilkhanian, M. Moradi, A. Pakseresht, M.S. Asl, H. Karimi-Maleh, H.W. Jang, M. Shokouhimehr, R.S. Varma, Biocompatibility and mechanical properties of pigeon bone waste extracted natural nano-hydroxyapatite for bone tissue engineering, Materials Science and Engineering: B 264 (2021) 114950.

[53] M. Radmansouri, E. Bahmani, E. Sarikhani, K. Rahmani, F. Sharifianjazi, M. Irani, Doxorubicin hydrochloride - Loaded electrospun chitosan/cobalt ferrite/titanium oxide nanofibers for hyperthermic tumor cell treatment and controlled drug release, International Journal of Biological Macromolecules 116 (2018) 378-384. 
[54] Y.-T. Xie, J.-R. Chen, Y.-T. Chen, B.-C. Jiang, Z.-H. Sie, H.-Y. Hsu, T.-L. Chen, Y.-Y. Chiang, H.-Y. Hsueh, Sol-gel-derived hierarchically wrinkled mesoporous ceramics for enhancement of cell alignment, Chemical Engineering Journal 405 (2021) 126572.

[55] L. Bazli, H. Nargesi khoramabadi, A. Modarresi Chahardehi, H. Arsad, B. Malekpouri, M. Asgari Jazi, N. Azizabadi, Factors influencing the failure of dental implants: a systematic review, Journal of Composites and Compounds 2(2) (2020). [56] C. Gong, D. Chen, X. Jiao, Q. Wang, Continuous hollow $\alpha-\mathrm{Fe}_{2} \mathrm{O}_{3}$ and $\alpha$-Fe fibers prepared by the sol-gel method, Journal of Materials Chemistry 12(6) (2002) 1844-1847.

[57] H.-W. Kim, H.-E. Kim, J.C. Knowles, Fluor-hydroxyapatite sol-gel coating on titanium substrate for hard tissue implants, Biomaterials 25(17) (2004) 33513358 .

[58] F. Baino, E. Fiume, M. Miola, E. Verné, Bioactive sol-gel glasses: Processing, properties, and applications, International Journal of Applied Ceramic Technology 15(4) (2018) 841-860.

[59] Z. Goudarzi, N. Parvin, F. Sharifianjazi, Formation of hydroxyapatite on surface of $\mathrm{SiO}_{2}-\mathrm{P}_{2} \mathrm{O}_{5}-\mathrm{CaO}-\mathrm{SrO}-\mathrm{ZnO}$ bioactive glass synthesized through sol-gel route, Ceramics International 45(15) (2019) 19323-19330.

[60] Z. Amini, S.S. Rudsary, S.S. Shahraeini, B.F. Dizaji, P. Goleij, A. Bakhtiari, M. Irani, F. Sharifianjazi, Magnetic bioactive glasses/Cisplatin loaded-chitosan (CS)-grafted- poly ( $\varepsilon$-caprolactone) nanofibers against bone cancer treatment, Carbohydrate Polymers 258 (2021) 117680

[61] Z. Goudarzi, A. Ijadi, A. Bakhtiari, S. Eskandarinezhad, N. Azizabadi, M.A. Jazi, Sr-doped bioactive glasses for biological applications, Journal of Composites and Compounds 2(3) (2020) 105-109.

[62] R. Gupta, A. Kumar, Bioactive materials for biomedical applications using sol-gel technology, Biomedical Materials 3(3) (2008) 034005.

[63] T. Dippong, E.A. Levei, O. Cadar, A. Mesaros, G. Borodi, Sol-gel synthesis of $\mathrm{CoFe}_{2} \mathrm{O}_{4}: \mathrm{SiO}_{2}$ nanocomposites - insights into the thermal decomposition process of precursors, Journal of Analytical and Applied Pyrolysis 125 (2017) 169-177.

[64] L. Zhao, Y. Wu, S. Chen, T. Xing, Preparation and characterization of crosslinked carboxymethyl chitin porous membrane scaffold for biomedical applications, Carbohydrate Polymers 126 (2015) 150-155.

[65] M. Catauro, F. Bollino, F. Papale, S. Marciano, S. Pacifico, $\mathrm{TiO}_{2} / \mathrm{PCL}_{\text {hybrid }}$ materials synthesized via sol-gel technique for biomedical applications, Materials Science and Engineering: C 47 (2015) 135-141.

[66] H. Ghazanfari, S. Hasanizadeh, S. Eskandarinezhad, S. Hassani, M. Sheibani, A. Dordsheikh Torkamani, B. Fakić, Recent progress in materials used towards corrosion protection of $\mathrm{Mg}$ and its alloys, Journal of Composites and Compounds 2(5) (2020).

[67] M. Catauro, S. Vecchio Ciprioti, Sol-Gel Synthesis and Characterization of Hybrid Materials for Biomedical Applications, in: C. Demetzos, N. Pippa (Eds.), Thermodynamics and Biophysics of Biomedical Nanosystems: Applications and Practical Considerations, Springer Singapore, Singapore, 2019, pp. 445-475.

[68] M.E. Astaneh, A. Goodarzi, M. Khanmohammadi, A. Shokati, S. Mohandesnezhad, M.R. Ataollahi, S. Najafipour, M.S. Farahani, J. Ai, Chitosan/gelatin hydrogel and endometrial stem cells with subsequent atorvastatin injection impact in regenerating spinal cord tissue, Journal of Drug Delivery Science and Technology 58 (2020) 101831

[69] M.S. Hasnain, A.K. Nayak, Alginate-inorganic composite particles as sustained drug delivery matrices, Applications of Nanocomposite Materials in Drug Delivery, Elsevier2018, pp. 39-74.

[70] H. Ullah, F. Wahid, H.A. Santos, T. Khan, Advances in biomedical and pharmaceutical applications of functional bacterial cellulose-based nanocomposites, Carbohydrate polymers 150 (2016) 330-352.

[71] S. Ebrahimi-Barough, J. Ai, M. Payab, S. Alavi-Moghadam, A. Shokati, H.R. Aghayan, B. Larijani, B. Arjmand, Standard Operating Procedure for the Good Manufacturing Practice-Compliant Production of Human Endometrial Stem Cells for Multiple Sclerosis, (2020).

[72] M. Catauro, M.G. Raucci, D. de Marco, L. Ambrosio, Release kinetics of ampicillin, characterization and bioactivity of $\mathrm{TiO}_{2} / \mathrm{PCL}$ hybrid materials synthesized by sol-gel processing, Journal of Biomedical Materials Research Part A 77A(2) (2006) 340-350.

[73] M. Lin, H. Wang, S. Meng, W. Zhong, Z. Li, R. Cai, Z. Chen, X. Zhou, Q. $\mathrm{Du}$, Structure and Release Behavior of PMMA/Silica Composite Drug Delivery System, Journal of Pharmaceutical Sciences 96(6) (2007) 1518-1526.

[74] M. Catauro, M. Raucci, G. Ausanio, Sol-gel processing of drug delivery zirconia/polycaprolactone hybrid materials, Journal of Materials Science: Materials in Medicine 19(2) (2008) 531-540.

[75] S. Sakai, T. Ono, H. Ijima, K. Kawakami, Proliferation and Insulin Secretion Function of Mouse Insulinoma Cells Encapsulated in Alginate/Sol-Gel Synthe- sized Aminopropyl-Silicate/Alginate Microcapsule, Journal of Sol-Gel Science and Technology 28(2) (2003) 267-272.

[76] M. Catauro, F. Bollino, F. Papale, M. Gallicchio, S. Pacifico, Synthesis and chemical characterization of new silica polyethylene glycol hybrid nanocomposite materials for controlled drug delivery, Journal of Drug Delivery Science and Technology 24(4) (2014) 320-325

[77] M. Catauro, D. Naviglio, R. Risoluti, S. Vecchio Ciprioti, Sol-gel synthesis and thermal behavior of bioactive ferrous citrate-silica hybrid materials, Journal of Thermal Analysis and Calorimetry 133(2) (2018) 1085-1092.

[78] M. Catauro, F. Barrino, G.D. Poggetto, F. Pacifico, S. Piccolella, S. Pacifico, Chlorogenic acid/PEG-based organic-inorganic hybrids: A versatile sol-gel synthesis route for new bioactive materials, Materials Science and Engineering: C 100 (2019) 837-844.

[79] F. Bollino, M. Catauro, Organic Inorganic Hybrid Materials Synthesized via Sol-Gel for Controlled Drug Delivery, Macromolecular Symposia 389(1) (2020) 1900059.

[80] S.O. Mezan, A.H. Jabbar, M.Q. Hamzah, A.N. Tuama, N.N. Hasan, M.S. Roslan, M.A. Agam, Synthesis, characterization, and properties of polystyrene/ $\mathrm{SiO}_{2}$ nanocomposite via sol-gel process, AIP Conference Proceedings 2151(1) (2019) 020034.

[81] I.A. Rahman, V. Padavettan, Synthesis of Silica Nanoparticles by Sol-Gel: Size-Dependent Properties, Surface Modification, and Applications in Silica-Polymer Nanocomposites-A Review, Journal of Nanomaterials 2012 (2012) 132424. [82] K. Krukiewicz, J.K. Zak, Biomaterial-based regional chemotherapy: Local anticancer drug delivery to enhance chemotherapy and minimize its side-effects, Materials Science and Engineering: C 62 (2016) 927-942.

[83] E.V. Parfenyuk, E.S. Dolinina, Design of silica carrier for controlled release of molsidomine: Effect of preparation methods of silica matrixes and their composites with molsidomine on the drug release kinetics in vitro, European Journal of Pharmaceutics and Biopharmaceutics 88(3) (2014) 1038-1045.

[84] M. Iafisco, N. Margiotta, Silica xerogels and hydroxyapatite nanocrystals for the local delivery of platinum-bisphosphonate complexes in the treatment of bone tumors: A mini-review, Journal of Inorganic Biochemistry 117 (2012) 237-247.

[85] R. Mellaerts, J.A.G. Jammaer, M. Van Speybroeck, H. Chen, J.V. Humbeeck, P. Augustijns, G. Van den Mooter, J.A. Martens, Physical State of Poorly Water Soluble Therapeutic Molecules Loaded into SBA-15 Ordered Mesoporous Silica Carriers: A Case Study with Itraconazole and Ibuprofen, Langmuir 24(16) (2008) 8651-8659.

[86] M. Prokopowicz, Formulation, characterisation and in vitro studies of doxorubicin-loaded silica-polydimethylsiloxane granules, European Journal of Pharmaceutical Sciences 66 (2015) 10-19.

[87] H. Qu, S. Bhattacharyya, P. Ducheyne, Silicon oxide based materials for controlled release in orthopedic procedures, Advanced Drug Delivery Reviews 94 (2015) 96-115

[88] M. Prokopowicz, A. Szewczyk, R. Łunio, W. Sawicki, Monolithic polydimethylsiloxane-modified silica composites prepared by a low-temperature sol-gel micromolding technique for controlled drug release, Reactive and Functional Polymers 114 (2017) 136-145.

[89] K.J. Klabunde, J. Stark, O. Koper, C. Mohs, D.G. Park, S. Decker, Y. Jiang, I. Lagadic, D. Zhang, Nanocrystals as Stoichiometric Reagents with Unique Surface Chemistry, The Journal of Physical Chemistry 100(30) (1996) 12142-12153.

[90] W. Stöber, A. Fink, E. Bohn, Controlled growth of monodisperse silica spheres in the micron size range, Journal of Colloid and Interface Science 26(1) (1968) 62-69.

[91] T. Matsoukas, E. Gulari, Monomer-addition growth with a slow initiation step: A growth model for silica particles from alkoxides, Journal of Colloid and Interface Science 132(1) (1989) 13-21.

[92] H. Nargesi khoramabadi, M. Arefian, M. Hojjati, I. Tajzad, A. Mokhtarzade, M. Mazhar, A. Jamavari, A review of Polyvinyl alcohol / Carboxiy methyl cellulose (PVA/CMC) composites for various applications, Journal of Composites and Compounds 2(3) (2020).

[93] T. Matsoukas, E. Gulari, Dynamics of growth of silica particles from ammonia-catalyzed hydrolysis of tetra-ethyl-orthosilicate, Journal of Colloid and Interface Science 124(1) (1988) 252-261

[94] G.H. Bogush, C.F. Zukoski, Studies of the kinetics of the precipitation of uniform silica particles through the hydrolysis and condensation of silicon alkoxides, Journal of Colloid and Interface Science 142(1) (1991) 1-18.

[95] E.V. Parfenyuk, E.S. Dolinina, Development of Novel Warfarin-Silica Composite for Controlled Drug Release, Pharmaceutical Research 34(4) (2017) 825835.

[96] J. Stergar, U. Maver, M. Bele, L. Gradišnik, M. Kristl, I. Ban, NiCu-silica nanoparticles as a potential drug delivery system, Journal of Sol-Gel Science and 
Technology (2020).

[97] M.I. Vlasenkova, E.S. Dolinina, E.V. Parfenyuk, Preparation of mesoporous silica microparticles by sol-gel/emulsion route for protein release, Pharmaceutical Development and Technology 24(2) (2019) 243-252.

[98] M. Boffito, A. Torchio, C. Tonda-Turo, R. Laurano, M. Gisbert-Garzarán, J.C. Berkmann, C. Cassino, M. Manzano, G.N. Duda, M. Vallet-Regí, K. SchmidtBleek, G. Ciardelli, Hybrid Injectable Sol-Gel Systems Based on Thermo-Sensitive Polyurethane Hydrogels Carrying pH-Sensitive Mesoporous Silica Nanoparticles for the Controlled and Triggered Release of Therapeutic Agents, Frontiers in Bioengineering and Biotechnology 8(384) (2020).

[99] Y. Zamani, A. Zareein, L. Bazli, R. NasrAzadani, B. Pasha Mahammod, S. Nasibi, A. Modarresi Chahardehi, Nanodiamond-containing composites for tissue scaffolds and surgical implants: A review, Journal of Composites and Compounds 2(5) (2020).

[100] S. Gao, M. Fan, Z. Li, K. Ge, X.-J. Liang, J. Zhang, Smart calcium peroxide with self-sufficience for biomedicine, Sci China Life Sci 63 (2020) 152-156.

[101] R. Sun, M. Åhlén, C.-W. Tai, É.G. Bajnóczi, F. de Kleijne, N. Ferraz, I. Persson, M. Strømme, O. Cheung, Highly porous amorphous calcium phosphate for drug delivery and bio-medical applications, Nanomaterials 10(1) (2020) 20.

[102] E. Kolanthai, V.S. Dikeshwar Colon, P.A. Sindu, V.S. Chandra, K.R. Karthikeyan, M.S. Babu, S.M. Sundaram, M. Palanichamy, S.N. Kalkura, Effect of solvent; enhancing the wettability and engineering the porous structure of a calcium phosphate/agarose composite for drug delivery, RSC Advances 5(24) (2015) 18301-18311.

[103] N.G.M. Palmqvist, J.-M. Nedelec, G.A. Seisenbaeva, V.G. Kessler, Controlling nucleation and growth of nano- $\mathrm{CaCO}_{3}$ via $\mathrm{CO}_{2}$ sequestration by a calcium alkoxide solution to produce nanocomposites for drug delivery applications, Acta Biomaterialia 57 (2017) 426-434

[104] C.-Y. Huang, T.-H. Huang, C.-T. Kao, Y.-H. Wu, W.-C. Chen, M.-Y. Shie, Mesoporous Calcium Silicate Nanoparticles with Drug Delivery and Odontogenesis Properties, Journal of Endodontics 43(1) (2017) 69-76.

[105] S. Ghadiri, S.A. Hassanzadeh-Tabrizi, A. Bigham, The effect of synthesis medium on structure and drug delivery behavior of CTAB-assisted sol-gel derived nanoporous calcium-magnesium-silicate, Journal of Sol-Gel Science and Technology 83(1) (2017) 229-236.

[106] S. Nasibi, K. Alimohammadi, L. Bazli, S. Eskandarinezhad, A. Mohammadi, N. Sheysi, TZNT alloy for surgical implant applications: A systematic review, Journal of Composites and Compounds 2(3) (2020).

[107] M. Prokopowicz, A. Szewczyk, A. Skwira, R. Sądej, G. Walker, Biphasic composite of calcium phosphate-based mesoporous silica as a novel bone drug delivery system, Drug Delivery and Translational Research 10(2) (2020) 455-470. [108] A. Szewczyk, A. Skwira, M. Prokopowicz, Drug-loaded mesoporous silica/ calcium phosphate composites for bone regeneration, Engineering of Biomaterials 22 (2019).

[109] S.-W. Tsai, S.-S. Huang, W.-X. Yu, Y.-W. Hsu, F.-Y. Hsu, Fabrication and Characteristics of Porous Hydroxyapatite-CaO Composite Nanofibers for Biomedical Applications, Nanomaterials 8(8) (2018) 570.

[110] C.M. Lopatin, V. Pizziconi, T.L. Alford, T. Laursen, Hydroxyapatite powders and thin films prepared by a sol-gel technique, Thin Solid Films 326(1) (1998) 227-232.

[111] M.H. Fathi, A. Hanifi, V. Mortazavi, Preparation and bioactivity evaluation of bone-like hydroxyapatite nanopowder, Journal of Materials Processing Technology 202(1) (2008) 536-542.

[112] S.-W. Tsai, W.-X. Yu, P.-A. Hwang, S.-S. Huang, H.-M. Lin, Y.-W. Hsu, F.-Y. Hsu, Fabrication and Characterization of Strontium-Substituted Hydroxyapatite- $\mathrm{CaO}-\mathrm{CaCO}_{3}$ Nanofibers with a Mesoporous Structure as Drug Delivery Carriers, Pharmaceutics 10(4) (2018) 179.

[113] B. K. Purushothaman, M. Harsha S, P.U. Maheswari, K.M.M. Sheriffa Begum, Magnetic assisted curcumin drug delivery using folate receptor targeted hybrid casein-calcium ferrite nanocarrier, Journal of Drug Delivery Science and Technology 52 (2019) 509-520.

[114] P. Ducheyen, L.L. Hench, The processing and static mechanical properties of metal fibre reinforced bioglass, Journal of Materials Science 17(2) (1982) 595-606. [115] H. Duan, C. Cao, X. Wang, J. Tao, C. Li, H. Xin, J. Yang, Y. Song, F. Ai, Magnesium-alloy rods reinforced bioglass bone cement composite scaffolds with cortical bone-matching mechanical properties and excellent osteoconductivity for load-bearing bone in vivo regeneration, Scientific Reports 10(1) (2020) 18193. [116] A. Bakhtiari, A. Cheshmi, M. Naeimi, S.M. Fathabad, M. Aliasghari, A.M. Chahardehi, S. Hassani, V. Elhami, Synthesis and characterization of the novel 80S bioactive glass: bioactivity, biocompatibility, cytotoxicity, Journal of Composites and Compounds 2(4) (2020) 110-114.

[117] L. Zhou, L. Fan, F.-M. Zhang, Y. Jiang, M. Cai, C. Dai, Y.-A. Luo, L.-J.
Tu, Z.-N. Zhou, X.-J. Li, C.-Y. Ning, K. Zheng, A.R. Boccaccini, G.-X. Tan, Hybrid gelatin/oxidized chondroitin sulfate hydrogels incorporating bioactive glass nanoparticles with enhanced mechanical properties, mineralization, and osteogenic differentiation, Bioactive Materials 6(3) (2021) 890-904.

[118] M. Miola, E. Verné, C. Vitale-Brovarone, F. Baino, Antibacterial Bioglass-Derived Scaffolds: Innovative Synthesis Approach and Characterization, International Journal of Applied Glass Science 7(2) (2016) 238-247.

[119] C. Wu, Z. Zhang, K. Zhou, W. Chen, J. Tao, C. Li, H. Xin, Y. Song, F. $\mathrm{Ai}$, Preparation and characterization of borosilicate-bioglass-incorporated sodium alginate composite wound dressing for accelerated full-thickness skin wound healing, Biomedical Materials 15(5) (2020) 055009.

[120] D. Durgalakshmi, R. Ajay Rakkesh, B. Subramanian, Bioactive assessment of bioactive glass nanostructures synthesized using synthetic and natural silica resources, International Journal of Applied Ceramic Technology 17(4) (2020) 19761984.

[121] M.S. Araujo, A.C. Silva, J.F. Bartolomé, S. Mello-Castanho, Structural and

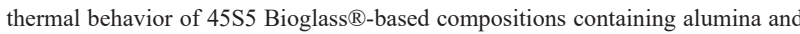
strontium, Journal of the American Ceramic Society 103(6) (2020) 3620-3630.

[122] A. Moghanian, A. Ghorbanoghli, M. Kazem-Rostami, A. Pazhouheshgar, E. Salari, M. Saghafi Yazdi, T. Alimardani, H. Jahani, F. Sharifian Jazi, M. Tahriri, Novel antibacterial $\mathrm{Cu} / \mathrm{Mg}$-substituted 58S-bioglass: Synthesis, characterization and investigation of in vitro bioactivity, International Journal of Applied Glass Science 11(4) (2020) 685-698.

[123] R. Li, A.E. Clark, L.L. Hench, An investigation of bioactive glass powders by sol-gel processing, Journal of Applied Biomaterials 2(4) (1991) 231-239.

[124] F. Sharifianjazi, M. Moradi, A. Abouchenari, A.H. Pakseresht, A. Esmaeilkhanian, M. Shokouhimehr, M. Shahedi Asl, Effects of Sr and Mg dopants on biological and mechanical properties of $\mathrm{SiO}_{2}-\mathrm{CaO}-\mathrm{P}_{2} \mathrm{O}_{5}$ bioactive glass, Ceramics International 46(14) (2020) 22674-22682.

[125] F. Sharifianjazi, N. Parvin, M. Tahriri, Synthesis and characteristics of solgel bioactive $\mathrm{SiO}_{2}-\mathrm{P}_{2} \mathrm{O}_{5}-\mathrm{CaO}-\mathrm{Ag}_{2} \mathrm{O}$ glasses, Journal of Non-Crystalline Solids 476 (2017) 108-113.

[126] A.R. Boccaccini, M. Erol, W.J. Stark, D. Mohn, Z. Hong, J.F. Mano, Polymer/bioactive glass nanocomposites for biomedical applications: A review, Composites Science and Technology 70(13) (2010) 1764-1776.

[127] K. Zhang, Q. Van Le, Bioactive glass coated zirconia for dental implants: a review, Journal of Composites and Compounds 2(2) (2020).

[128] F. Sharifianjazi, N. Parvin, M. Tahriri, Formation of apatite nano-needles on novel gel derived $\mathrm{SiO}_{2}-\mathrm{P}_{2} \mathrm{O}_{5}-\mathrm{CaO}-\mathrm{SrO}-\mathrm{Ag}_{2} \mathrm{O}$ bioactive glasses, Ceramics International 43(17) (2017) 15214-15220.

[129] C. Vichery, J.-M. Nedelec, Bioactive Glass Nanoparticles: From Synthesis to Materials Design for Biomedical Applications, Materials 9(4) (2016) 288.

[130] K. Zheng, A.R. Boccaccini, Sol-gel processing of bioactive glass nanoparticles: A review, Advances in Colloid and Interface Science 249 (2017) 363-373.

[131] A. Lukowiak, J. Lao, J. Lacroix, J.-M. Nedelec, Bioactive glass nanoparticles obtained through sol-gel chemistry, Chemical Communications 49(59) (2013) 6620-6622.

[132] X. Wang, Y. Zhang, C. Lin, W. Zhong, Sol-gel derived terbium-containing mesoporous bioactive glasses nanospheres: In vitro hydroxyapatite formation and drug delivery, Colloids and Surfaces B: Biointerfaces 160 (2017) 406-415.

[133] S.A. Hassanzadeh-Tabrizi, A. Bigham, M. Rafienia, Surfactant-assisted solgel synthesis of forsterite nanoparticles as a novel drug delivery system, Materials Science and Engineering: C 58 (2016) 737-741.

[134] P. Horcajada, A. Rámila, J. Pérez-Pariente, R. Vallet, x, M., Influence of pore size of MCM-41 matrices on drug delivery rate, Microporous and Mesoporous Materials 68(1) (2004) 105-109

[135] M. Schumacher, L. Reither, J. Thomas, M. Kampschulte, U. Gbureck, A. Lode, M. Gelinsky, Calcium phosphate bone cement/mesoporous bioactive glass composites for controlled growth factor delivery, Biomaterials Science 5(3) (2017) 578-588.

[136] Y. Wang, H. Pan, X. Chen, The Preparation of Hollow Mesoporous Bioglass Nanoparticles With Excellent Drug Delivery Capacity for Bone Tissue Regeneration, Frontiers in Chemistry 7(283) (2019).

[137] S.A.M. El-Sayed, M. Mabrouk, M.E. Khallaf, B.M. Abd El-Hady, E. El-Meliegy, M.R. Shehata, Antibacterial, drug delivery, and osteoinduction abilities of bioglass/chitosan scaffolds for dental applications, Journal of Drug Delivery Science and Technology 57 (2020) 101757.

[138] R.B.Z. Auniq, N. Hirun, U. Boonyang, Three-Dimensionally Ordered Macroporous-Mesoporous Bioactive Glass Ceramics for Drug Delivery Capacity and Evaluation of Drug Release, Ceramic Materials, IntechOpen2020.

[139] M.S.U. Rahman, M.A. Tahir, S. Noreen, M. Yasir, I. Ahmad, M.B. Khan, K.W. Ali, M. Shoaib, A. Bahadur, S. Iqbal, Magnetic mesoporous bioactive glass 
for synergetic use in bone regeneration, hyperthermia treatment, and controlled drug delivery, RSC Advances 10(36) (2020) 21413-21419.

[140] M.S. ur Rahman, M.A. Tahir, S. Noreen, M. Yasir, M.B. Khan, T. Mahmood, A. Bahadur, M. Shoaib, Osteogenic silver oxide doped mesoporous bioactive glass for controlled release of doxorubicin against bone cancer cell line (MG-63): In vitro and in vivo cytotoxicity evaluation, Ceramics International 46(8, Part A) (2020) 10765-10770.

[141] S. Shanmugasundar, N. Kannan, E. Sundaravadivel, S. Zsolt, K. Mukunthan, J. Manokaran, J. Narendranath, V. Kamalakannan, P. Kavitha, V. Prabhu, Study on the inflammatory response of PMMA/polystyrene/silica nanocomposite membranes for drug delivery and dental applications, PloS one 14(3) (2019) e0209948. [142] Y. Wang, H. Pan, X. Chen, The preparation of hollow mesoporous bioglass nanoparticles with excellent drug delivery capacity for bone tissue regeneration, Frontiers in chemistry 7 (2019) 283.

[143] A. Bigham, S. Hassanzadeh-Tabrizi, A. Khamsehashari, A. Chami, Surfactant-assisted sol-gel synthesis and characterization of hierarchical nanoporous merwinite with controllable drug release, Journal of Sol-Gel Science and Technology 87(3) (2018) 618-625.

[144] M. Shoaib, M.S. ur Rahman, A. Saeed, M.M. Naseer, Mesoporous bioactive glass-polyurethane nanocomposites as reservoirs for sustained drug delivery, Colloids and Surfaces B: Biointerfaces 172 (2018) 806-811.

[145] Y. Zhang, X. Wang, Y. Su, D. Chen, W. Zhong, A doxorubicin delivery system: Samarium/mesoporous bioactive glass/alginate composite microspheres, Materials Science and Engineering: C 67 (2016) 205-213.

[146] P. Abasian, M. Radmansouri, M. Habibi Jouybari, M.V. Ghasemi, A. Mohammadi, M. Irani, F.S. Jazi, Incorporation of magnetic NaX zeolite/DOX into the PLA/chitosan nanofibers for sustained release of doxorubicin against carcinoma cells death in vitro, International Journal of Biological Macromolecules 121 (2019) 398-406.

[147] C. Soundrapandian, B. Sa, S. Datta, Organic-Inorganic Composites for Bone Drug Delivery, AAPS PharmSciTech 10(4) (2009) 1158-1171.

[148] A. Ratier, I.R. Gibson, S.M. Best, M. Freche, J.L. Lacout, F. Rodriguez, Setting characteristics and mechanical behaviour of a calcium phosphate bone cement containing tetracycline, Biomaterials 22(9) (2001) 897-901.

[149] A. Bordbar-Khiabani, S. Ebrahimi, B. Yarmand, In-vitro corrosion and bioactivity behavior of tailored calcium phosphate-containing zinc oxide coating prepared by plasma electrolytic oxidation, Corrosion Science 173 (2020) 108781. [150] E. Jablonská, D. Horkavcová, D. Rohanová, D.S. Brauer, A review of in vitro cell culture testing methods for bioactive glasses and other biomaterials for hard tissue regeneration, Journal of Materials Chemistry B 8(48) (2020) 10941-10953. [151] T.J. Mäkinen, M. Veiranto, P. Lankinen, N. Moritz, J. Jalava, P. Törmälä, H.T. Aro, In vitro and in vivo release of ciprofloxacin from osteoconductive bone defect filler, Journal of Antimicrobial Chemotherapy 56(6) (2005) 1063-1068.

[152] E.J.A. Pope, K. Braun, C.M. Peterson, Bioartificial organs I: Silica gel encapsulated pancreatic islets for the treatment of diabetes mellitus, Journal of SolGel Science and Technology 8(1) (1997) 635-639.
[153] G. Carturan, R. Campostrini, S. Dire, V. Scardi, E. De Alteriis, Inorganic gels for immobilization of biocatalysts: inclusion of invertase-active whole cells of yeast (Saccharomyces cerevisia) into thin layers of $\mathrm{SiO}_{2}$ gel deposited on glass sheets, J. mol. catal 57(1) (1989) L13-L16.

[154] G. Carturan, R. Dal Toso, S. Boninsegna, R. Dal Monte, Encapsulation of functional cells by sol-gel silica: actual progress and perspectives for cell therapy, Journal of Materials Chemistry 14(14) (2004) 2087-2098.

[155] S. Sakai, T. Ono, H. Ijima, K. Kawakami, Modification of porous aminopropyl-silicate microcapsule membrane by electrically-bonded external anionic polymers, Journal of Biomaterials Science, Polymer Edition 14(7) (2003) 643-652. [156] S. Sakai, T. Ono, H. Ijima, K. Kawakami, MIN6 cells-enclosing aminopropyl-silicate membrane templated by alginate gels differences in guluronic acid content, International Journal of Pharmaceutics 270(1) (2004) 65-73.

[157] H. Hu, X. Wang, K.I. Lee, K. Ma, H. Hu, J.H. Xin, Graphene oxide-enhanced sol-gel transition sensitivity and drug release performance of an amphiphilic copolymer-based nanocomposite, Scientific Reports 6(1) (2016) 31815.

[158] E. Kolanthai, K. Ganesan, M. Epple, S.N. Kalkura, Synthesis of nanosized hydroxyapatite/agarose powders for bone filler and drug delivery application, Materials Today Communications 8 (2016) 31-40.

[159] A. Abbaszad Rafi, M. Mahkam, S. Davaran, H. Hamishehkar, A Smart pH-responsive Nano-Carrier as a Drug Delivery System: A hybrid system comprised of mesoporous nanosilica MCM-41 (as a nano-container) \& a pH-sensitive polymer (as smart reversible gatekeepers): Preparation, characterization and in vitro release studies of an anti-cancer drug, European Journal of Pharmaceutical Sciences 93 (2016) 64-73.

[160] M. Ghazaie, P. Ghiaci, M. Ghiaci, Study on release of naproxen and metformin encapsulated in biopolymer-inorganic mesoporous matrices as controlled drug-delivery systems, Microporous and Mesoporous Materials 244 (2017) 291300 .

[161] K. S, R. Rama Pawar, B. D Kevadiya, H. C Bajaj, Synthesis of Saponite Based Nanocomposites to Improve the Controlled Oral Drug Release of Model Drug Quinine Hydrochloride Dihydrate, Pharmaceuticals (Basel) 12(3) (2019) 105.

[162] C.Y. Gong, S. Shi, P.W. Dong, X.L. Zheng, S.Z. Fu, G. Guo, J.L. Yang, Y.Q. Wei, Z.Y. Qian, In vitro drug release behavior from a novel thermosensitive composite hydrogel based on Pluronic f127 and poly(ethylene glycol)-poly( $\varepsilon$-caprolactone)-poly(ethylene glycol) copolymer, BMC Biotechnology 9(1) (2009) 8.

[163] B. Kundu, C. Soundrapandian, S.K. Nandi, P. Mukherjee, N. Dandapat, S. Roy, B.K. Datta, T.K. Mandal, D. Basu, R.N. Bhattacharya, Development of New Localized Drug Delivery System Based on Ceftriaxone-Sulbactam Composite Drug Impregnated Porous Hydroxyapatite: A Systematic Approach for In Vitro and In Vivo Animal Trial, Pharmaceutical Research 27(8) (2010) 1659-1676. [164] M. Safari, M. Ghiaci, M. Jafari-Asl, A.A. Ensafi, Nanohybrid organic-inorganic chitosan/dopamine/ $\mathrm{TiO}_{2}$ composites with controlled drug-delivery properties, Applied Surface Science 342 (2015) 26-33 